\title{
DIE 'KETZERPLAKATE' KAISER KARLS IN DEN \\ NIEDERLANDEN UND IHRE BEDEUTUNG FÜR BIBELÜBERSETZUNGEN IN DER VOLKSSPRACHE: \\ DER 'PROTO-INDEX' VON 1529 ALS VORLÄUFIGER ENDPUNKT
}

\author{
Wim François \\ Leuven
}

Dass konservative Löwener Theologen bei der Entstehung der Reformation in den Niederlanden mit einem absoluten Verbot des Bibellesens in der Landessprache reagiert hätten, ist in wisscnschaftlichen Kreisen allmählich (wenn auch nicht übcrall) in das Reich der Fabeln verwiesen. In diesem Artikcl möchten wir die 'Bibelpolitik' vorstellen, so, wie sic in den "Ketzerplakaten" Kaiser Karls zum Ausdruck kam. Wir beschränken uns dabei auf die allererste Periode, ungefähr das erste Jahrzehnt nach dem Aufkommen des reformatorischer Ideen in den Niederlanden. Dabei kann das Plakat von 1529 als wichtiger Wendepunkt betrachtet werden. Es bot eine

${ }^{1}$ Für den Text der Plakate: Paul Fredericq, Hg., Corpus documentorum Inquisitionis haereticae pravitaits Neerlandicae. Verzameling van stukken betreffende de pauselijke en bisschoppelijke Inquisitie in de Nederlanden. Band 4: Tijdvak der Henomming in de zestiende eeure (1514-23 september 1525) (Gent, 1900); Band 5: Tijdvak der Hervorming in de zestiende eeuw. Eerste vervolg (24 september 1525-31 december 1528) (Gent, 1902). Siche auch: Charles Laurent, Jules Lameere und Henri Simont, Hg., Recueil des ordonnances des Pays-Bas. Deuxième série: 1507-1700. Band 2: Charles Laurent und Jules Lameere, Hg., Contenant les ordonnances du 29 janvier 1519 au 31 décembre 1529. (Brüssel, 1898); Band 3: Jules Lameere, Hg., Conlenant les ordonnances du 8 jamier 1529 (1530, N.ST.) au 11 décembre 1536 (Brüssel, 1902). Eine Besprechung der Edikte und Plakate findet man u.a. in Aline Goosens, Les inquisitions modemes dans les Pays-Bas méridionaux 15201633. Band 1: La législation [Spiritualités et pensées libres] (Brüssel, 1997), S. 47-81; Jochen A. Fühner, Die Kirchen- und die antireformatorische Religionspolitik Kaiser Karls V. in den siebzehn Provinzen der Niederlande, 1515-1.55.5 (unvcröffentlichte Dissertation Ph.D., Universität Heidelberg, 2002), erscheint in Brill's Series in Church History, Band 23 (Leiden, 2004). Siehe auch das ältere, aber immer noch brauchbare Werk: Franz Heinrich Reusch, Der Index der verbotenen Bücher. Ein Beitrag zur Kirchen- und Literaturgeschichte, Band 1 (Bonn, 1883), S. 98-113. Eine obcrflächliche und oft umstrittenc Analyse der Plakate bietet: Louis Augustine Kenney, The Censorship Edicts of Emperor Charles $V$ in the Low Countries, 1515-1550 (unveröffentlichte Dissertation Ph.D., University of Maryland, 1960). Dank gilt dem Herrn Alois Greiler für seine außerordentliche Mitarbeit an der Übersetzung des vorliegenden Beitrags. 
Synthesc der Politik bezüglich verbotener Bücher, wie sie in den Jahren zuvor ausgearbeitet worden ist. Auch war es der Maßstab, der in späteren Jahren noch angewandt wurde. Das Plakat von 1529 bezcichnet zudem einen wichtigen Schritt in der Entwicklung eines Index der verbotenen Bücher, wie ihn Löwener Theologen entwickelt haben. Bei der Besprechung der Plakate aus den ersten zehn Jahren werden wir jeweils die Bibelausgaben ${ }^{2}$ berücksichtigen, wie sie in den Nicderlanden zirkulierten und gebraucht wurden. ${ }^{3}$

\section{Das Edikt von Worms und die Buchzensur}

In den frühen zwanziger Jahren des sechzehnten Jahrhunderts "fanden Bibeln und reformatorische Literatur, durch eifrige Buchhändler verbreitet, reißenden Absatz. Für die Durchsetzung der neuen Ideen waren dic Gruppen der Bibelleser wichtig, dic sich an vielen Orten gebildet haben". "Die weltlichen und geistlichen Autoritäten in den Niederlanden versuchten dann auch ihrerseits, die Verbreitung und die Publikation von Büchern (c.q. Bibeln) zu kontrollieren. Die Bekämpfung verbotener Litcratur ging selbstredend einher mit dem Verbot von Zusammenkünften, bei denen diese neuen theologischen Ideen besprochen oder weitergegeben würden.

Die für die Nicderlande bestimmte Fassung des Wormser Edikts (Mai 1521) verhängte im Grunde die Strafen, die das Kirchenrecht,

${ }^{2}$ Für die verschiedenen Bibelausgaben dieser Periode siehe vor allem Cebus Cornelis de Bruin, De Statenbijbel en zïn voorgangers. Nederlandse bübelwertalingen vanaf de Reformatie tot 1637, bearbeitct durch Frits Gerrit Murk Broeyer (Haarlem, 1993); Aurelius Augustinus den Hollander, De Nederlandse bijbelvertalingen. Dutch Translations of the Bible 1522-1545 [Bibliotheca Bibliographica Neerlandica 33] (Nicuwkoop, 1997). Ferner: Simon Willem Bijl, Erasmus in het Nederlands tot 1617 [Bibliotheca Bibliographica Neerlandica 10] (Nieuwkoop, 1978).

${ }^{3}$ In diesem Zusammenhang siche auch: Aurelius Augustinus den Hollander, Verboden bïbels. Bübelcensuur in de Nederlanden in de eerste helft van de zestiende eeuwe: [Oraticrecks] (Amsterdam, 2003).

${ }^{4}$ Johan Decavcle, De dageraad van de reformatie in Vlaanderen. Band 1: tekst [Verhandelingen van de Koninklijke Academie voor Wetenschappen, Letteren en Schone Kunsten van Belgiö: Klasse der Letteren 76| (Brüssel, 1975), S. 298 (unsere Übcrsetzung). Siche auch Cornclis Augustijn, 'Die Ketzerverfolgungen in den Nicderlanden von 1520 bis 1545', in Ketzenierfolgung im 16. und frïhen 17. Fahrhundert, $\mathrm{Hg}$. Silvana Seidel Menchi [Wolfenbütteler Forschungen 51] (Wiesbaden, 1992), S. 53: "Dic Geschichte der Reformation in den Niederlanden ist bis in dic fünfziger Jahrc zum Großtcil eine Geschichte der Druckerpresse".

${ }^{5}$ Für die ursprünglich lateinische Version des Wormser Ediktes: Fredericc, Hg., Corpus Inquisitionis, Band 4 (siehe oben, Anm. 1), S. 47-58. Die niederländische Fassung für die Niederlande aus der Feder Jean Hannarts, Karls Sekretär: Fredericq, 
auf Basis des römischen Rechtes, für Ketzerei und Majestätsbeleidigung vorsah, namentlich die Todesstrafe und damit zusammenhängend die Konfiszierung der Güter. Dies galt unverkennbar auch für die, die das Verbot, reformatorische Bücher zu besitzen, übertraten ("op de verbucrte van live ende van goede"). Die Plakate, die im Verlauf der zwanziger Jahre verkündet wurden, waren am Anfang im Ton allerdings milder und scheinen sinngemäß auf die ursprüngliche, die latcinische Version des Wormser Ediktes zurückzugchen. Für die Übertretungen wurde nicht so einfach die Todesstrafe verhängt. Auch für die Übertretung des Buchverbotes wurde die durch die niederländische Version des Wormser Edikts ausdrücklich vorgesehene Sanktion, nämlich die Konfiszierung von Leib und Gut, nicht in all seiner Strenge verlangt. Außerdem wurde jetzt allgemein davon ausgegangen, dass dic Magistrate in den Niederlanden eher lax gegen Personen mit abweichenden Ideen vorgingen, und dass dies sicherlich da der Fall war, wo der Buchandel betroffen war. Es waren vor allem geschulte Leute mit ihrem Hang zum Bücherwissen, die sich durch das Bücherverbot hart getroffen fühlten. Die Tatsache, dass ja einige Magistratsmitglieder in den Städten und Juristen in den Provinzräten zur gleichen humanistisch inspirierten Oberschicht gehörten, erklärt für Alastair Duke u.a. dic Zurückhaltung letzterer, dic Plakatc in all ihrer Strenge anzuwenden. ${ }^{6}$ Den Buchhandel zu schützen war für cinc Stadt wie Antwerpen auch eine wirtschaftliche Notwendigkeit. Dennoch würde man die Kontrolle über Druckerzeugnisse - und da vor allem über Ausgaben der Heiligen Schrift in den Ketzerplakaten der zwanziger Jahre (und später) auf immer explizitere Weise anstrcben. Die für Übertretung vorgesehenen Strafen wurden allmählich auch strenger. Nach Bücherverbrennungen blieben stets ketzerische Schriften über, die von Hand zu Hand gingen und

Hg., Corpus Inquisitionis, Band 4, S. 58-76; Laurent und Lameere, Hg., Recueil des ordonnances, Band 2 (siehe oben, Anm. 1), S. 73-83. Vom französischen Text des Ediktes, aus dem Niederländischen von Aleander übersetzt, gibt es noch keine vollständige Ausgabe. Eine gründliche Untersuchung der Unterschied zwischen dem lateinischen Text und denen für die Niederlande bietet: Fühner, Die Niederlande (siehe oben, Anm. 1), S. 164-169. Auch: Den Hollander, Verboden bijbels (siehe oben, Anm. 3), S. 6-7; Ernest Persoons, 'Edikt van Worms, 8 mei 1521. Speciale tekst voor de Nederlanden. Franse versie', in Doorheen de nationale geschiedenis. Permanente tentoonstelling, Hg. Carlos Wyffels, Band 1 (Brüssel, 1980), S. 124-126.

${ }^{6}$ Alastair C. Duke, Reformation and Revolt in the Low Countries (London, 1990), S. 158; Henk F.K. Van Nierop, 'Censorship, Illicit Printing and the Revolt of the Netherlands', in Too Mighty to be Free. Censorship and the Press in Britain and the Netherlands, Hg. Alastair C. Duke und Coenraad Arnold 'Tamse ('/utphen, 1987), S. 36-37; 39. 
den vielen Gruppen von 'Bibellesern', die überall in den Niederlanden entstanden, als Gesprächsgrundlage dienten. Wir könnnen keine detaillierte Besprechung aller Plakate aus der zweiten Hälfte der zwanziger und Anfang der dreißiger Jahre geben ${ }^{7}$ und beschränken uns darum auf einige wichtige Phasen in der Entwicklung, wobei wir uns insbesondere auf deren Auswirkung auf die Veröffentlichung von Bibelausgaben in den Niederlanden konzentrieren.

\section{Die Plakate gegen Bibelübersetzungen mit Glossen, Summarien und/oder Vorreden}

Auf einem Plakat, das allein für Holland, Seeland und Friesland bestimmt war und auf den 23. März $1524^{8}$ datiert ist, musste die Regentin im Namen des Kaisers feststellen, dass, trotz der Verkündigung des Ediktes von Worms und dessen Bestimmungen gegen 'ketzerische' Bücher, bestimmte Drucker dennoch verdächtige Werke gedruckt und verkauft und dass viele Menschen diese Bücher gekauft und gelesen hatten. Viclleicht reagierte die Regicrung mit diesen Worten auch auf die eher laxe Anwendung der Buchzensur in holländischen Städten wie Amsterdam und Delft. Im neucn Plakat von 1524 fällt auf, dass ein ausdrückliches Verbot des "Evangcliums nach dem $\mathrm{Hl}$. Matthäus" ("t Ewangelie van Ste. Matheus") samt dem ihm beigefügten Glossen ausgesprochen wird. ${ }^{9}$ Höchstwahrscheinlich ging es hicr um cine Ausgabe des Matthäusevangeliums, die 1522 durch den Amsterdamer Drucker Doen Pietersoen herausgebracht wurde. Allgemein wurde angenommen, dass die Übersetzung dieses Evangeliums von Johan Pelt stammt, Guardian des Klosters der Minderbrüder in Amsterdam und später evangelischer Prediger in Bremen. Sie stellt die allererste niederländische Bibelübersetzung dar, die sich nicht auf einen existierenden mittelalterlichen Text bezog, sondern eine Neuübersetzung bot. Johan Pelt nahm den Vulgatatext als Grundlage. Wo dieser unklar war, berief er sich auf die lateinische Version von Erasmus' Novum Testamentum von 1519. Der Text der Glossen folgte

7 Siche auch: Fühner, Die Niederlande (siehe oben, Anm. 1), S. 187.

" Fredericq, Hg., Corpus Inquisitionis, Band 4 (siehe oben, Anm. 1), S. 265-266.

9 "...t Ewangelic: van Ste Matheus mit die glose dair inne gestelt, overmidts dat tselfde qualijcken getranslatecrt is ende dat inde glosen zekere dwalingen bevonden zijn geweest..." (Fredericq, Hg., Corpus Inquisitionis, Band 4 (sichc obcn, Anm. 1), S. 266). 
denen von Erasmus' Anmerkungen und den Erklärungen des Nikolaus von Lyra $(\dagger 1340)$, die selbst wiederum sich in vielen Fällen auf die Glossa ordinaria stützten - im Mittelalter die Bibelerklärung mit der größten Autorität. Der Einfluss des Humanismus eines Erasmus auf die Kommentare ist deutlich, was u.a. aus dem oft wiederkehrende Anspruch sichtbar wird, die Schrift auch für Laien zugänglich zu machen. ${ }^{10}$ Neben diesem Evangelium wurde durch den Frlass vom März 1524 auch "Die Somme van die godlycke gescriften" verboten. Gemcint ist die Summa der Godliker Scrifturen oft een duytsche Theologie, cin frühreformatorisches Werk, das 1523 bei Jan Seversz. in Leiden crschien. Die traditionelle Zuordnung an Henricus Bomelius als Autor ist sehr unsicher. Wie der Titel angibt, wollte der Verfasser mittels einer Zusammenfassung des Inhalts der Schrift den Kern des christlichen Glaubens vorstellen. Dic Rechtfertigung durch Glauben allein wird darin bekräftigt und der Verdienst durch gute Werke abgelehnt. Außerdem gab die Summa Richtlinien hinsichtlich des persönlichen und gesellschaftlichen Lebens der Christen. Nicht unwichtig ist, dass der Autor in verschiedenen Passagen auch dafür plädierte, dass alle Menschen von Kindesbeinen an mit dem Lesen der Bibel in ihrer eigenen Sprache vertraut gemacht werden sollten. Dieses Werk hat eine große Verbreitung erfahren, und dic Buchzensur hatte es bestimmt im Blick." Die Exemplare dieses und anderer ohne

in De Bruin, De Statenbijbel (siehe oben, Anm. 2), S. 67-72; Den Hollander, De Nederlandse bïbeluertalingen (siehe oben, Anm. 2), S. 39-40; 212; 261-263; Bijl, lirasmus in hel Nederlands (siehe oben, Anm. 2), S. 12-30. Siehe auch: Johannes Trapman, De Summa der Godliker Scrifturen (1.523) (Leiden, 1978), S. 109-111. Zu diskutieren bleibt der Tenor dieser Ausgabe. De Bruin betont, der zwar erst junge, aber doch ausgesprochen reformatorische Charakter des 'Textes werde besonders aus den Anmerkungen oder den 'Glosscn' am Schluss jedes Kapitels und vor allem aus "dem Schlusswort des Übersetzers" ("die Conclusie des Translatocrs ofte Overstelders") deullich. Bijl seinerseits bezweifelt, ob der Ubersetzer, Johan Pelt, damals reformatorisch genannt werden könne. Der Autor betont, wic Pelt in diesem Moment ganz dem Einfluss des Humanismus eines trasmus' unterstand und dass dics auch aus seinen Glossen dcutlich wird. Allerdings gesteht Bijl zu, dass in "die Conclusie des Translatoers oftc Overstelders" Ideen Luthers durchkämen. Ausdrücklich wird betont, dass der sündige Mensch nicht durch scine eigenen Werke gercchtfertigt werden kann, sondern durch die Gnade und die Verdienste Jesu Christi, der für die Menschen am Kreuz gestorben ist. Dic Verdienste Jesu Christi, zugleich ein Vorbild der Nachfolge für alle Christen, kann man durch das Wort der Schrift kennen lernen. Diese Nachrede ist nach Bijl cin Vorbote der Richtung, dic Johan Pelt später cinschlagen solte. Auch J. Trapman betont, dass Pelts Mattäusevangelium streng genommen nicht reformatorisch genannt werden kann und verweist unter anderem auf scine Auffassung der Heiligen Messe. Trapman bezeichnet diese Fidition als ausgesprochen erasmianisch.

11 Trapman, De Summa (siehe oben, Anm. 10). 
Autorisicrung im Umlauf befindlicher Werke mussten innerhalb einer Frist von acht Tagen vernichtet werden. In Übercinstimmung mit dem Edikt von Worms blieb es fortan verboten, weiterhin diese Art Bücher zu drucken, zu verkaufen, zu kaufen oder zu lesen. Bei wem nach Ablauf dieser Acht-Tage-Frist noch ein solches Werk gefunden wurde, der sollte "an Leib und an Gut" bestraft werden. Dabei wurde allerdings ausdrücklich die Möglichkeit offen gehalten, das Strafmaß "an die konkrcten Umstände des Falles" ("nae gelegentheyt vanden saicke") anzupassen. ${ }^{12}$ Beide der auf diesem Plakat aufgeführten Werke genicßen die zweifelhafte Ehre, die ersten Titel gewcsen zu sein, dic in den Niederlanden auf eincr Liste verbotener reformatorisch eingestellter Schriften standen.

Am 1. April 1524 folgte das, was man eine Ergänzung des Plakates von der Woche zuvor nennen könnte. ${ }^{13}$ Der Zentralregicrung wünschte, dass in Holland, Sccland und Friesland nochmals deutlich verkündet würde, niemand dürfe Bücher verlegen, es sei denn, er habe von der zuständigen Behörde (Statthalter, Vorsitzender und Rat von Holland) ausdrücklich die Zulassung dafür bekommen. Und dies mit dem Risiko "gestraft zu werden an ihrem Leib oder Gütern nach den jeweiligen Umständen" ("op peyne van gestraft te worden van huere lyven ofte goeden nac gclegentheyt vander saken"). ${ }^{1+}$ Dic Zentralregierung in Mechelen wollte dafür sorgen, dass keine Bücher mehr in Umlauf kämen, die Irrlehren oder Ketzereien enthielten. Alle Gcrichtsbcamten wurden ausdrücklich zur Mitarbeit an der Ausführung des Plakates ermahnt und mussten darübcr hinaus auch beim Statthalter, Vorsitzenden und Mitgliedern des Rates von Holland Bericht erstatten.

Selbstverständlich betraf die Buchzensur vor allem Antwerpen. Bereits am 15. Februar 1522 hatte der Magistrat der Stadt eine Verdordnung erlassen, dic das Wormser Edikt an die Antwerpener Situation anpasssen sollte. Am 14. Februar 1525 folgte cine neue Verordnung, an die Drucker, Buchbinder und Buchhändler der Stadt gerichtet. ${ }^{15}$ Ausgangspunkt war die Feststellung, dass in der Stadt viele Bücher im Umlauf waren, die nicht vorab durch die Zensoren

\footnotetext{
12 Fredericq, Hg., Corpus Inquisitionis, Band 4 (siehe oben, Anm. 1), S. 266.

13 Ibid., S. 268-269.

it Ibid., S. 269.

${ }^{15}$ Ibid., S. 309-310; Pierre Génard, Hg., Antwerpsch Archievenblad, Band 2 (Antwerpen, s.d.), S. 314-315.
} 
genehmigt worden waren (darunter auch Ausgaben des Neuen Testamentes). Die städtische Verordnung erinnerte darum nochmals an das Edikt von Worms und die damit verbundenen Sanktionen ("verbeurte van lyve ende van goeden"). Bevor in Antwerpen ein Buch, das über die Heilige Schrift und ihre Auslegung handelte, gedruckt oder verkauft werden konnte, musste deshalb erst die Genehmigung des Ortsordinarius eingeholt werden, der wiederum mit den Theologen der Löwener Universität Rücksprache halten musste. ${ }^{16}$ Für ein Buch, das nicht eine Glaubenslehre behandelte, bedurfte es der vorausgehenden Zulassung durch den Markgrafen oder den Statthalter. Zudem musste in jedem in Antwerpen gedruckten Buch der Name des Autors, das Erscheinungsdatum, sowie Name, Zeichen und Adresse des Druckers cnthalten sein. Letztere Bedingungen galten auch für Bücher, dic außerhalb Antwerpens gedruckt, aber in der Stadt gebunden und verkauft wurden. Ähnliche $\Lambda$ nordnungen wurden später für die ganzen Niederlande erlassen. Die Drucker, Buchbinder und Buchhändler, die diese Vorschriften nicht befolgten, wurden mit der Konfiszierung der Bücher deren Herkunft und Genehmigung der Zensoren nicht nachgewiesen werden konnten, und außerdem mit dem Verlust ihres Bürgerstatus und den damit verbundenen Rechten, und einer zehnjährigen Verbannung aus Stadt und Markgrafschaft (oder einer nach Gutdünken der Richter festgelegten Strafe) bestraft. Falls dic vorgcschricbenen Angaben über Autor, Drucker, Datum und Erscheinungsort nicht mit der Wahrheit übereinstimmten, waren die selben Strafen vorgesehen. Doch scheint es, dass derlei Anordnungen nicht viel Eindruck machten. Was unser Thema betrifft, so kann betont werden, dass Neue Testamente und später Vollbibeln, dic auf der Lutherübersetzung basierten, in Antwerpen gedruckt werden konnten.

Am 24. September 1525 stelltc dic Regentin im Namen des Kaisers das sogenannte dritte große Plakat gegen die Lutheraner aus, wiederum für Holland, Seeland und Friesland bestimmt. ${ }^{17}$ Nur wenige Monate später, am 17. Juli 1526, wurde für Flandern das vierte Plakat veröffentlicht, eine gegenüber dem ursprünglichen 'holländischen Edikt' leicht erweiterte und verschärfte Version. ${ }^{18}$ Es enthielt eine

16 "eest materie der heiliger scriftucren aengaende, dat hy dan yerst sal moeten hebben consent vanden Ordinarys met approbatien vander Universiteyt van Loven, metter selver seghel beseghelt ..." (Fredericq, Hg., Corpus Inquisitionis, Band 4 (siehe oben, Anm. 1), S. 310).

17 Fredericq, Hg., Corpus Inquisitionis, Band 5 (siehe oben, Anm. 1), S. 1-5.

${ }^{18}$ Laurent und Lamecre, Hg., Recueil des ordonnances, Band 2 (siehe oben, Anm. 1), 
auffällige Einlcitung, die den Ursprung der herrschenden Irrlehren und Ketzereien andeutete. Hingewiesen wird auf Prediger, die auf der Kanzel die Irrlehren Luthers und anderer Ketzer vortrugen, und dadurch das Volk erst auf die Ideen der Reformatoren, die sie zuvor noch nicht gehört oder gelesen hatten, aufmerksam machten. Ziel dieser Aussage war es natürlich, die Prediger zu größter Vorsicht zu ermahnen. Angespielt wurde auf individuelles Lesen und Interpretieren der Bibel, aber auch auf die Lektüre und die Diskussion der Schrift und der Predigten in allerlei kleinen Gruppen ${ }^{19}$ oder 'Konventikeln'. ${ }^{20}$ Diese Konventikel seien "stark besuchte Zusammenkünfte in Wohnungen, Herbergen, Kähnen oder auf dem freien Feld", ${ }^{21}$ wo selbst

S. 402-405; Fredericq, Hg., Corpus Inquisitionis, Band 5 (siehe oben, Anm. 1), S. 142-148. Fine summarische Auflistung der Lnterschicde bci Goosens, Les inquisitions, Band 1 (siehe oben, Anm. 1), S. 51. Im Regierungsbezirk Lille, Douai und Orchies wurde die Verordnung am 5. Juli 1527 verkündet (Ibid., S. 52).

${ }^{19}$ Schon mal wird suggeriert, dass der spanische Habsburger Karl durch die Haltung der spanischen Kirche bezüglich der Übersetzungen in dic Volkssprachen beeinflusst gewesen sein könnte. In Spanien soll auf Initiative der katholischen Fürsten Ferdinand und Isabella cin strenges Verbot für Übersetzungen der Bibcl in der Volkssprache crschicnen sein. Papst Paul II. (1464-1471) soll diese Maßnahme ausdrücklich gutgeheißen haben. Diese Schilderung der 'Tatsachen beruft sich vor allem auf das Werk Adversus omnes haereses (1534) des Kontroverstheologen Alphonso de Castro (Ferdinand Cavallera, 'La Bible en langue vulgaire au Concile de Trente (IV" Session)', in Mélanges E. Podéchard. Etudes de sciences religizuses offertes pour son éméritat au doyen honoraire de la Faculte de Théologie de Lyon (Lyon, 1945), 37-56, S. 41; 46). Verschiedene Arbeiten haben allerdings Fragezeichen hinter die Existenz eines solchen absoluten Verbotes in Spanien gesetzt. Das Verbot soll sich vornehmlich auf die neubekchrten Christen jüdischer Herkunft bezogen haben. Bei ihnen bestand das Risiko, dass sie aufgrund ihres religiosen Hintergrundes, der einer christologischen Lesart der Schrift und darin vor allem der Psalmen keinen Raum gab, Übersetzungen in dic Volkssprache unkontrolliert interpretieren könnten. Anschließend wurden in Spanien auch die Übersetzungen in Blick genommen, die direkt auf die hebräische Bibel zurückgingen und darum dic Glaubenswahrheiten, wie die Vulgata sie bot, vernachlässigten (Vgl. u.a: Jesús Enciso, 'Prohibiciones españolas de las versiones bíblicas en romance antes del Tridentino', Estudios Bíblicos 3 (1944), 523-554, S. 537-541; Robert E. McNally, 'The Council of Trent and Vernacular Bibles', Theological Studies 27 (1966), 204-227, S. 215).

20 Zur aufkommenden individuellen Lesekultur und dem Gespräch über das Gelesene während der Konventikel vgl. besonders: Willem Heijting, "Ziet daer staedt ghescreven ende 't es zo". Het boek en de overdracht van ideeën bij de eerste Nederlandse evangelisch gezinden', in Mensen van de Nieuze Tijd. Fen liber amicorum voor A.Th. van Deursen, Hg. M. Bruggeman et al. (Amsterdam, 1996), S. 1428. Ferner: Augustijn, 'Die Ketzerverfolgungen' (siehe oben, $\Lambda$ nm. 4), S. 55; 59; Decavele, De dageraad (siche oben, Anm. 4), S. 108; 193-196; Duke, Reformation and Revolt (siehe oben, Anm. 6), S. 38-39; 115-117.

${ }^{21}$ Heijting, "Ziet daer staedt ghescreven ende 't es zo"' (siehe oben, Anm. 20), S. 17 (unsere Übersetzung). 
des Schreibens Unkundige die Schrift und Kommentare dazu in ihrer eigenen Sprache vorgelesen bekamen. In Flandern (und Holland) nahmen oft auch dic Versammlungen der Rhetoriker den Charakter solcher Konventikel an. ${ }^{22}$ Die in diesem Zusammenhang geführten Glaubensgespräche waren übrigens nicht nur ein Medium, um die neue Lehre weiterzugeben, sondern geradezu cinc Brutstätte neuer Ideen. Verschiedene größere Städte der Niederlande waren mit dem Auftauchen dieser semi-klandestinen Konventikel oder frühen Hauskirchen konfrontiert. ${ }^{23}$ Allerdings ist es nicht so, als hätte sich in der von uns untersuchten Periode eine parallele Struktur evangelischer Gemeinden gebildet. Wir können davon ausgehen, dass dic meisten der Menschen mit diesen ncuen Ideen wie gewohnt den katholischen Gottesdiensten beiwohnten, die Sakramente empfingen und das Fasten-

22 Decavele, De dageraad (siche oben, Anm. 4), S. 195.

${ }^{23}$ In der Literatur finden sich zahlreiche Beispiele von solchen Konventikeln. Davon nennen wir drei, die sich ausdrücklich mit der Lektüre und Kommentierung der Bibcl in der Landessprache befasst haben. So fand Anfang 1524 in Antwerpen im Eyckstraetken ein geheimes Treffen mit ungefähr 30 Personen statt, "dacrmen lesse gedaen ende gheinterpreteert hecft de heylighe Eeuwangelien ende andere heylige schriften, contraric den gheboden vander Keyserlicke Majesteyt". Als Vorsitzender dieser Zusammenkunft fungierte "Adriaen, de schildere". Die Teilnehmer an diesem Konventikel waren allesamt Handwerker (Fredericq, Hg., Corpus Inquisitionis, Band 4 (siehe oben, Anm. 1), S. 259-261; 266-267; Génard, Hg., Antwerpsch Archievenblad, Band 2 (siehe oben, Anm. 15), S. 312-314; Band 7, S. 129-133; auch: De Bruin, De Statenbizbel (siehe oben, Anm. 2), S. 132). Der Amsterdamer Prediger Claes van der Elst leitete um 1525 im Haus des Schultheißen Jan Huybrechtsz während der Mahlzcit Gespräche über die Heilige Schrift (De Bruin, De Statenbijbel, S. 134). Auch die Stadt Kortrijk war schon vor der Verkündigung des Plakates mit solchen Konventikeln konfrontiert, wobei besonders die Bibellcktüre in der Volkssprache eine wichtige Rolle spielte: "Eine äußerst bemerkenswertc städtische Vcrordnung vom 24. Juli 1524 spricht davon, dass dic neuen Ideen in Kortrijk damals schon weit verbreitet waren. Der Magistrat dieser Stadt hatte erfahren, dass einige Einwohner, Männer wie auch Frauen, rcgelmäBig in Privathäusern zusammenkamen, um 'Flämische oder Wallonische Bücher, übersetzt aus den heiligen Schriften und der Theologie' zu lesen und sich darüber gegenseitig ihre Gedanken auszutauschen. Dic Existenz dieser Gruppe und die Namen ihrer Mitglieder waren in Kortrijk allgemein bekannt, sogar so, dass man den Bibcllesern auf der Straß3e hinterherrief und Schimpflieder auf sic verfasste. Dass sogar der einfache Mann auf der Straße sich der Andersartigkeit der Bibelleser bewusst war, belegt ausreichend, dass Kortrijk bereits geraume Zeit vor 1524 mit der neuen Lehre in Berührung gekommen ist. Das frühe Vcrbot crweckt den Eindruck, als ob es dem Magistrat vor allem darum ging, dic innere Ordnung und Ruhe in der Stadt herzustellen. Wer das Wort Gottes ausgelegt hören wollte, wurde ermahnt, nicht mehr an den Konventikeln teilzunehmen, sondern den Predigten in den Kirchen beizuwohnen. Es wurde den Spöttern ihrerseits fortan verboten die Bibelleser zu beschimpfen. Aus dieser Verordnung kann man keinen zu starken Ton gegen die 'Neuerer' heraushören" (Decavele, De dageraad (siche oben, Anm. 4), S. 287; unsere Übersetzung). 
und Abstinenzgebot einhielten. ${ }^{2+}$ In Anspielung auf diese Konventikel sagte der Plakattext, dass Menschen ohne Befugnis oder Zulassung ihrer kirchlichen Oberen als Prcdigcr aufträten, in geheimen Zusammenkünften das Evangelium verkündigten und die Schrift gemäß ihrer eigenen Auffassungen und nicht gemäß der rechten Lehre, wie sie durch die Kirchenväter und die Theologen festgelegt sei, interpretierten. ${ }^{25}$ Nicht nur Prediger traten auf, auch gewöhnliche Laien und solche ohne Schulbildung lasen täglich (als Einzelne) das Evangelium in der Landessprache, verstanden es gemäß ihrer eigenen Einsicht und gingen allein vom Wort aus "gemäß dem Buchstaben" ("naer de lettere"), ohne sich von der offiziellen Schriftinterpretation der Kirche leiten zu lassen. Und es gab noch mehr: Auf allerlei Treffen (die eben besprochenen Konventikel) diskutierten diese Laien frei über das, was sie gelesen hatten. Im Plakattext sehen wir, ${ }^{26}$ dass ein Kontrast zwischen einerseits einer Auslegung gemäß der eigenen Einsicht und dem Wortlaut und andererseits einer Auslegung gemäß den Auffassungen der rechten Lehre der Kirche aufgebaut wurde. Der Tenor des Plakates ist klar: Ein freier Umgang mit der Schrift, besonders durch Menschen ohne Ausbildung, ist der Kcim aller Ketzerei.

Durch dieses Plakat wurde dann auch ein Verbot allerlei halboffizieller oder auch informeller Treffen mit dem Zweck, die Bibel in der Landessprache zu lesen, sie nach eigener Anschauung zu interpretieren oder darüber zu diskutieren, erlassen. ${ }^{27}$ Es versteht sich von

24 Dies unterstreicht Augustijn, 'Die Ketzerverfolgungen' (siehe oben, Anm. 4), S. 58-59. Vgl.: Decavele, De dageraad (siche oben, Anm. 4), S. 269; 277; 284; Duke, Reformation and Revolt (siche oben, Anm. 6), S. 39; 85-86.

25 ". . . eensdecls by toedoene van eeneghe ongheleerde, dic zonder consent van hucren hueversten int heymelicke ende scerctelicken predicken dic Evangelien, die midgaders ander heleghe gheschriften interpreterende nae huere zinnelicheyt ende niet naer den rechten verstande van den docteurs van der helegher Kercke, ..." (Laurent und Lameere, Hg., Recueil des ordonnances, Band 2 (siche oben, Anm. 1), S. 403).

26 "Ooc zoo verstaen wy dat de voorseyde dolinghen ende erreuren eensdeels toecommen ende ghevoet worden uut dien dat leecke, simple ende ongheleerde persoonen de walsche ende vlaemsche Evangelien ende andere heleghe gheschrificn lesen naer hueren verstande ende naer de lettere, danof met elcanderen ende by vergaderinghen diverssche disputatien hebbende, nemende tghuent at hemlieden behaghelicst es, ende niet attenderende ten rechten verstande..." (I aurent und Lamcere, Hg., Recueil des ordonnances (siehe oben, Anm. 1), Band 2, S. 403).

${ }_{27}$ Unerlaubte Zusammenkünfte durften nicht gehalten werden, "omme aldaer te lezen, spreken, confereren ofte predicken van den cvangelien, cpistelen van Sinte Pauwels, of andere gheschriften van der helegher schriften, in latyne, vlaemsche ofte 
selbst, dass es auch verboten war, über andere sensible Themen der kirchlichen Lehre zu sprechen, die die lutherische Kontroverse bestimmten, wie Eucharistie, Beichte, Verehrung Marias und der Heiligen, Autorität des Konzils und/oder Papstes, das Gebet für die Verstorbenen und den Ablass. Auf solche verbotenen Konferenzen standen als Strafen Geldbußen, Hausarrest und auch Verbannung. Über cinc ausnahmslose Verhängung der Todesstrafe für Teilnehmer an solchen informellen Diskussionsgruppen sprach man in dem Moment nicht. Das Strafmaß auf dem Plakat für den Süden war noch etwas strenger als auf dem Plakat für Holland. Die örtlichen Gerichtsbehörden wurden ausdrücklich ermächtigt, die Strafen anzupassen, zu mindern oder zu vermehren, je nach dem wic es der Fall erforderte. ${ }^{28}$ Sobald aber Ketzerei im Spiel war, musste stets dem Urteil des Generalinquisitors Genüge getan werden.

Außcr den verbotenen Zusammenkünften oder Konventikeln versuchten die Autoritäten auch der Reformation nahe stehende Schriften aus dem Verkehr zu ziehen oder ihnen Einhalt zu bieten. Die kaiserliche Verwaltung verhängte dann auch eine strikte Zensur. Ausdrücklich verboten wurden zunächst die Werke Martin Luthers, Philipp Melanchthons, Johannes Oecolampadius' und die anderer Reformer wie François Lambert, Johann Bugenhagen (Pomeranus), Justus Jonas, Andreas Rudolf Bodenstcin von Karlstadt (Carolostadius). Diese Auflistung wirkt wie ein erster Schritt in Richtung eines Index verbotener Bücher..$^{29}$ Nur auf dem Plakat, dass auch für die südlichen Provinzen galt, war das Verbot ausgedehnt auf Bibelausgaben in Deutsch, Niederländisch oder Französisch, die Glossen, Anmerkungen und Einleitungen im Sinne der lutherischen Lehre enthielten. ${ }^{30}$

walsche; nochte aldaer de zelve te interpreteren oft opt verstandt van dien te disputeren ofte confereren, in wat manieren dattet zy" (Laurent und Lameere, Hg., Recueil des ordonnances (siehe oben, Anm. I), Band 2, S. 403).

${ }^{28}$ Fredericq, Hg., Corpus Inquisitionis, Band 5 (siehe oben, Anm. 1), S. 4; 146.

29 ". . for the first time it named authors besides Luther whose books were forbidden, a small but nevertheless distinct step on the way to an index of forbidden books" (Kenncy, The Censorship Edicts (siehe oben, Anm. 1), S. 117).

${ }^{30}$ ". . . ende alle evangelien, epistelen prophetien ende andere boucken van der helegher schrifturen, in duutsch, vlaemsch ofte walsche, gheappostilleert, ghegloseert, oft hebbende prefatie of prologuc, inhoudende dolinghen, erreuren ofte doctrine van den voorseyden Luther ende zyne adherenten, by der helegher Kercke ghercprobcert ofte repugnerende der ghemeene leeringhe ende doctrine van der zelver, wacr ende in wat plecken de zelve gheschreven ofte gheprent zyn,..." (Laurent und Lameere, Hg., Recueil des ordonnances, Band 2 (siehe oben, Anm. 1), S. 404). 
Merkwürdigerweise hatte man dieses Verbot nicht im ursprünglichen dritten Plakat aufgenommen, wie es im Norden erlassen worden war. Aus dieser Hinzufügung ergibt sich, dass die Autoritäten nicht an erster Stelle Bibelübersetzungen als solche im Sinn hatten, sondern vielmehr Übersetzungen, die lutherische Vorreden, Zusammenfassungen und Glossen, die sogenannten paratextuellen Elemente, cnthielten. Dieser Punkt ist von Bedeutung, weil er die Richtung angibt, in welche die Politik bezüglich der Bibelübersetzungen in den Niederlanden in Zukunft gehen sollte. ${ }^{31}$ Laut diesem Plakat mussten auch die Bücher aus dem Verkehr gezogen werden, dic ohne Titel oder anonym gedruckt waren ("zonder tytele"), eine Bestimmung, die wir sowohl in der älteren holländischen als auch in der späteren südlichen Version finden. Alle genannten Bücher musste man verbrennen, "te pulfere verberrent". ${ }^{2}$ Wer nach Veröffentlichung dieses Plakates dennoch ein solches Buch besaß, musste aus seinem Land verbannt werden und "sein Leben und Gut" wurden konfisziert. Auf den ersten Blick ist dics cine etwas verwirrende Kombination von zwei Strafen, Verbannung und die durch das Edikt von Worms für die Niederlande vorgeschriebene Todesstrafe, wobei erstere als eine mildernde Interpretation letzterer zu gelten schien und die Konfiszierung von "Leib und Güter" nur die Anwendung für die war, die nicht ins Exil gingen. ${ }^{33}$ Laut Plakat mussten auch ncue Bücher, die in den Niederlanden zum Druck gebracht oder von woanders her eingeführt wurden, eine ausdrückliche Genehmigung des Provinzrates erhalten, und dies unter Strafandrohung der Einziehung des dritten Teils der Güter und der Verbannung.

Schließlich wurde den Mcistern an den (Latein)Schulen strikt verboten, ihre Schüler mit den oben genannten Lehrmeinungen und Büchern in Kontakt zu bringen. Im Hintergrund stand, dass Schulmeister den Ruf hatten, kritische und unabhängige Geister zu sein und man befürchtete, dass sie diese Haltung ihren Schülern vermitteln

31 A. Goosens außert beim Plakat von 1526 nochmals das weitverbreitete Vorurteil, dass dieses Plakat das Lesen der Bibel in der Volkssprache für Laien verbot: ". . . il interdisait la lecture de la Bible par les simples laies..." (Goosens, Les inquisitions, Band 1 (siehe oben, Anm. 1), S. 51).

${ }^{32}$ Laurent und Lameere, Hg., Recueil des ordonnances, Band 2 (siehe oben, Anm. 1), S. 403 .

${ }^{33}$ Andrew G. Johnston, 'L'imprimerie et la Réforme aux Pays-Bas 1520-c. 1555', in La Reforme et le livre. L'Europe de l'imprimé (1517-v. 1570), Hg. Jcan-François Gilmont [Cerf Histoire] (Paris, 1990), S. 182. 
würden. ${ }^{3+}$ Das ursprüngliche Plakat für Holland hatte sogar noch aufgenommen, dass die Schulmeister an Sonn- und Feiertagen dic Lesung vom Tage allein aus grammatikalischer Sicht behandeln und nicht mehr inhaltlich auslegen sollten. ${ }^{35}$ In den Städten der nördlichen Niederlande war es üblich, dass die Schulrektoren und Fratres an Sonntagen und Heiligengedenktagen in geschlossener Zusammenkunft mit Schülern und Bürgern die Epistel und das Evangelium vom Tage lasen und erklärten. Solche Treffen entstanden aus der schriftbezogenen Spiritualität der Devotio modema heraus. Diese Schulmeister aber waren im Allgemeinen sehr aufnahmebereit für die neuen Ideen. Cebus Cornclis de Bruin meint, dass sic eine "alte Form benutzt haben, um etwas Neues zu gießen".

Das genannte Plakat musste auf öffentlichen Plätzen verkündet werden, und wer dagegen handelte, musste "schr rigoros und streng" ("zeer rigorueselick ende strengelick") bestraft werden. Dazu wurden "Offiziere, Justizbeamte und Untertanen" ("officieren, justicieren ende ondersaeten"), d.h. die örtlichen Bchörden beauftragt. ${ }^{37}$ In Anwendung dieser Plakate wurden übcrall in den Niederlanden Prozcsse geführt gegen (vermeintliche) Übertretungen des Verbotes, Bibeln und anderc Bücher zu lesen und während der Konventikel darüber zu sprechen. ${ }^{38}$

${ }^{34}$ Guido Marnef, Antweerpen in de tijd van de Reformatie. Ondergronds Protestantisme in een handelsmetropool 1550-1577 (Antwerpen, 1996), S. 63-64.

3i "... grammaticaliter ct non mistice" (Fredericq, Hg., Corpus Inquisitionis, Band 5 (siehe oben, Anm. 1), S. 4).

${ }_{36}$ De Bruin, De Siatenbijbel (siehe oben, Anm. 2), S. 63-64 (unsere Ubersetzung). Siehc auch: Duke, Reformation and Revolt (siche oben, Anm. 6), S. 13: "Apart from the language of instruction, there was little difference between the schoolmaster, who expounded the scriptures to his pupils and the bible-reading conventicles, which mushroomed in the towns after 1523. The authorities realised this and duly placed curbs on the former sort of assembly, while forbidding the latter".

${ }^{37}$ Fredericq, Hg., Corpus Inquistionis, Band 5 (siche oben, Anm. 1), S. 5; auch: S. 147. Die Aufgabe der ortlichen Behörden, Übertretungen streng mit den vorgeschricbenen Strafen zu ahnden, scheint im Gegensatz zur ersten Bestimmung dicses Plakates zu stehen, Bestrafungen je nach Einzelfall zu verschärfen oder zu mildern. Dass bereits der Statthalter und der Rat von Holland das Recht bekommen hätten, das Plakat den konkreten Umständen entsprechend zu interpretieren, macht cin ausdrückliches Schreiben des Landvogtes vom 25. Scptember 1525, dem Tag nach der Verkündigung der 'holländischen Version' des Plakates, deutlich (Ibid., S. 5-6).

${ }^{38}$ Ein sehr bekannter Fall ist der von Hector van Dommele, der um 1525 in der Pfarrei 'Unsere Liebe Frau' in Brügge die vielleicht crste reformatorische Gemeinschaft der Stadt gründete. J. Decavele schreibt über ihn: "Der Hutmacher van Dommele muss auf jeden Fall eine besondere Bildung genossen haben. Er las Latein, zitierte Bibeltexte und ihre Stellen auswendig und besaß eine große Bibliothck mit insbesondere lutherischen Schriften, aus denen er während der Zusammenkünfte 
Das Plakat, wie es bereits in Holland September 1525 verkündet war, blieb nicht ohne Folgen. Ein Auszug aus den Ausgaben des Hofes von Holland vom 18. November 1525 belegt, dass die Reisckosten für einen Boten vorgesehen waren, der durch den Hof zum Schultheiß von Amsterdam geschickt wurde mit dem ausdrücklichen Auftrag, "dass er gewisse Bücher der Briefe des Heiligen Paulus, gedruckt bei Doen Pietersz. verbrennen solle". ${ }^{39}$ Maria Elizabeth

vorlas. Vielleicht war er es, der dafür sorgte, dass auch die Glaubensgenossen mit Büchcrn ausgestattet wurden" (Decavele, De dageraad (siehe oben, Anm. 4), S. 251 252; unsere Ubersetzung). Auch die anderen Mitglicder dieser crsten reformatorischen Gemeinschaft waren beinahe alle Gewerbetreibende, Arbeitnehmer wie Arbeitgeber. Viele von ihnen hatten nach der Verkündigung des Plakates zwischen 1527 und 1531 mit den Gerichten zu tun. Van Dommele wurde 1527 gefassi. Im Gefängnis gab es einen Moment, wo er Zweifel hatte und kurz davor stand, seine 'kctzerischen' Überzeugungen zu widerrufen. Doch schöpte er neue Entschlossenheit aus der Lektüre des Neuen Testaments, dass ihm Glaubensbrüder heimlich in das Gefängnis gebracht hatten: "Maarten de Smct und Yzebrant Willem Diericxsz. reichten ihm aus einem leerstehendem Haus mit Blick auf das Gefängnis mit Hilfe eines langen Stocks das Testament hinüber. Sie hatten das Buch zuerst aufschneiden müssen, um es Teil für Teil durch das Gitterfenster zu bekommen" (Ibid., S. 252, Anm. 96; unsere Übersctzung). Van Dommele wurde zum hartnäckigen Ketzer crklärt und der weldichen Obrigkeit zur Bestrafung übergeben. Am 12. Oktober 1527 wurde er hingerichtet. 1531 creilte zwei andere Mitglieder dicser klcinen reformatorischen Gemeinschafi das gleiche L os. Anderen gegenüber, die sich reuevoll gezeigt hatten, verhielt sich dic Obrigkeit besonders milde. Merkwürdigerweise war es nicht die staatliche Inquisition, sondern die bischöfliche, nämlich der Brügger Offizial des Bistums Tournai, die die Sache in der Hand hatte. (Für cine ausfïhrlichere Darstellung des Falles vgl. ibid., S. 251-253). Ein anderes Mitglied derselben reformatorischen Gemeinschaft, der Brauer Jan Wytinc, wurde aus Brügge verbannt und ließ sich, wie es oft geschah, in Antwerpen nieder. Von da besuchte er 1528 Frankfurt. "Es gefiel ihm da so gut, dass er am 8. Oktober dieses Jahres den Rat der Stadt schriftlich um Aufnahme seiner Familie ersuchtc. Als Begründung für dicses Gesuch führte er an, dass jeder, der in Flandern oder in Brabant über das Evangelium spreche, von der Todesstrafe bedroht sei. Ihm nach war es dort sogar verboten, das Ncue Testament im Haus zu haben oder zu lesen" (Ibid., S. 253; unsere Ubersetzung). Die Stadı Ypern wurde weniger als Gent, Kortrijk und Brügge zu Beginn der Reformation mit Neugesinnten in ihren Mauern konfrontiert. Doch wurden auch da zwischen 1526 und 1529 eine Reihe von Prozessen gegen Neugesinnte geführt, die zusammenkamen, um in der Bibel zu lesen und um Gedanken aus den "livres suspectr." 7.u besprechen. Besonders im 'Westkwartier' und noch genauer im Gebiet Vcume-Poperinge-Hondschoote scheinen die ncucn Ideen in dieser Periode verbreitet gewesen zu sein, und dic Obrigkeit musste gegen zahlreiche Neugesinnte eingreifen, dic in Konventikeln zusammenkamen. Sint-Winoksbergen bildete ein wichtiges Zentrum, von wo aus Ketzer Druckerzeugnisse über das Westkwartier verbreiteten (Ibid., S. 280-286).

39 "dat hy zekere boucxkens van Sinte Pouwels epistelen geprent by Doen Pietersz. verbranden soude" (Fredericq, Hg., Corpus Inquisitionis, Band 5 (siehe oben, Anm. 1), S. 63; unscrc: Übersetzung). 
Kronenberg denkt, dass der zweite Teil des Neuen Testamentes von Doen Pietersoen von 1.523 gemeint sei. Dieser enthielt die allererste niederländische Übersetzung der Paulusbriefe und der katholischen Briefe, die auf dem Luthertext 1522 mit dessen Vorreden und Randbemerkungen gegründet war. Diese Glossen und Prologe wurden durch Doen Pietersoen außerdem auf der Titelscite angekündigt. ${ }^{40}$ Wie bereits angedeutet, waren es vor allem diese paratextuellen Elemente, in denen dic reformatorischen Ideen explizit verkündet wurden, die den Ärger der Krone hervorriefen. So braucht man sich nicht wundern, dass diese Ausgabe die Aufmerksamkeit der Gerichte auf sich zog.

Am 3. Dezember 1525 wurden durch die Schöffen und den Rat von Kampen - zu diesem Zeitpunkt noch kein Teil des Habsburger Reiches! - eine Anzahl Bücher aufgelistet, die binnen acht Tagen abgeliefert werden mussten. Darunter befand sich Die Duytsche theologie, ein Buch, das früher schon ins Gerede gebracht worden war, aber auch "das vor kurzem mit Glossen gedruckte Neuc Testament" ("het Nye Testament nycs gedruckt mitter gloesen"). ${ }^{+1}$ Für C. C. de Bruin, dem August Den Hollander in diesem Punkt folgt, ging es hier vermutlich um die Ausgabe des Neuen Testamentes, dic Albert Pafract 1525 in Deventer publiziert hatte. ${ }^{42}$ Im Sinne der damaligen Normen ging es hier um cine bösartige Ausgabe. Diese Ausgabe bot cine neue, 'saubere' Übersetzung von Luthers Neuem 'Testament, die sich übrigens von der von Adriaen van Berghen von 1523 (Evangelien, Apostelgeschichtc und Offenbarung) und der von Doen Pietersoen aus dem selben Jahr (Briefe) unterschied. Noch anstößiger waren, wie schon angedeutet, die reformatorischen Prologe und Anmerkungen. Von den drei Vorreden aus dem Vorspann waren zwei dem Reformator aus Wittenberg entlehnt. Für dic Briefe und dic Offenbarung fanden sich ebenfalls Luthers Vorreden in Übersetzung. Interlinear waren Anmerkungen oder Glossen angebracht, die fast immer cine wortgetreue Übersctzung von Luthers Anmerkungen

40 Maria Elizabeth Kroncnberg, 'Vervolging van kettersche boeken in de Nedcrlanden (c. 1518-1528), Het Boek. Tiweede reeks van het Tijdschrift voor Boek- en Bibliotheekuezen 16 (1927), 163-190, S. 178.

${ }^{+1}$ Fredericq, Hg., Corpus Inquisitionis, Band 5 (siehe oben, Anm. 1), S. 71 (unsere Übersetzung).

${ }^{12}$ De Bruin, De Statenbijbel (siehe oben, Anm. 2), S. 85-91; Den Hollander, De Nederlandse bijbelvertalingen (siehe oben, Anm. 2), S. 77; 222-223; 304-306; Den Hollander, Verboden bijbels (siehe oben, Anm. 3), S. 10. 
boten. Auch die Ausgabe von Pafraet kündigte diese (streng reformatorischen) Vorreden und Erklärungen auf dem Titelblatt an.

In Antwerpen hielt es der Magistrat am 29. Oktober 1526 für nötig, das für Druck, Verkauf, Lektüre oder Besitz ketzerischer Bücher und ebenfalls für Bücher mit verdächtiger Vorrede bestehende Verbot nochmals ausdrücklich zu verkünden. Diesc Bücher hatte man unverzüglich dem Magistrat auszuhändigen "optc pene van scerpelic, sonder verdrach, gccorrigeert te worddene".

Der Gouverncur von Friesland stellte scincrseits am 22. Dezember 1526 eine Ordonanz aus, in der er mit Berufung auf die kaiserlichen Edikte dem Magistrat von Lccuwarden befahl, binnen dreier Tage in der Stadt alle verbotenen Bücher zu beschlagnahmen und ihm zu übergeben, damit er sie verbrennen könnc. Die in der Ordonanz aufgeführten Autoren verbotener Bücher "in der Heyliger Scriften met Luther geuoclende" waren genau die gleichen wic die im Edikt von 1525. Wer dem Edikt nicht gehorchte, bekam, im verhältnis zu sein Delikt, eine schwere Strafe auferlegt. ${ }^{+4}$

Die Regentin Margarethe von Österreich hatte vernommen, dass das Luthertum sich im Hennegau verbreitete und dass dics unter anderem dic Schuld der Nachlässigkeit der Magistrate und Gerichtsbeamten sei. Darum richtete sic, einigermaßen irritiert, am 7. Märı 1527 ein Schreiben an den Großvogt des Hennegaus, in dem sic verlangte, das Plakat vom 22. März 1521 (!) nochmals ankündigen zu lassen, und den, der dagegen handelte, zu bestrafen. Nachlässige Gerichtsbeamte mussten aus ihrem Amt entfernt werden und außerdem eine gcbührende Strafe erhalten. ${ }^{45}$ Der Großvogt ließ das betreffende Plakat unmittclbar aufs Neue in Mons und anderen Städten des Hennegaus verkünden. ${ }^{+6}$ Auch der Rat von Flandern bekam von der Regentin den Auftrag, das Plakat vom 17. Juli 1526 erneut zu verbreiten, und dic Gerichtsdiener zu mehr Eifer bei der Verfolgung von Verstößen anzuspornen. ${ }^{+7}$ Am 14. März 1527 wurde in Holland das Plakat vom 24. Scptember 1525 nochmals neu verkündet. ${ }^{48}$ Eine

${ }^{43}$ Fredericq, Hg., Conpus Inquisitionis, Band 5 (siehe oben, Anm. 1), S. 154; Génard, Hg., Antwerpsch Archievenblad, Band 2 (siehe obcn, Anm. 15), S. 319.

${ }^{++}$Fredericq, Hg., Corpus Inquisitionis, Band 5 (siche oben, Anm. 1), S. 164-165.

+5 Ibid., S. 186-187.

th Ibid., S. 191.

${ }^{47}$ Goosens, Les Inquisitions, Band 1 (siehe oben, Anm. 1), S. 52.

${ }^{48}$ Fredericq, Hg., Corpus Inquisitionis, Band 5 (siehe oben, Anm. 1), S. 190. 
weitere Klärung dabei birgt ein Dokument, das die Landvögte zusammen mit den Dekanen von Löwen und Naaldwijk, Inquistoren, verfasst hatte, und das die Lage in Holland behandelte, und am 25. Mai 1527 dem Rat der Provinz, überreicht wurde. Auch hicr wird verlangt, dass die Gerichtsdiener, die sich all zu lax verhiclten, gemaßregelt würden. Verwiesen wird hier ausdrücklich auf den Schultheiß von Amstcrdam. ${ }^{19}$

Dic Aufgabe, in welchem Maße örtliche Gerichte das Recht hatten, dic durch das Plakat vorgesehenen Strafen entsprechend den Umständen des Einzelfalles anzupassen (abzumildern), gab hicr und da wohl Anlass zu Streitigkeiten. Fs scheint doch cine Spannung zwischen der Strenge der Plakatc und der Vollmacht örtlicher Richter, nach eigenem Ermessen cine Strafe aufzuerlegen ('arbitrale correctie') gegeben zu haben, wie dies das 'holländische' Plakat vom 24. September 1525 und 14. März 1527 klar ermöglichte. Noch 1527 bekräftigte der Vorsitzende des Großen Rates von Mcchelen, die höchste Berufungsinstanz der Niederlande, dass örtliche Gerichte die in den Plakaten wegen Ketzerei verhängten Strafen nicht ganz genau anwenden mussten, sondem die Umstände des Falles oder dic Situation der betroffenen Personen mitzubedenken waren, ob diese zum Beispiel für Kinder zu sorgen hatten und sic bei einer eventuellen Exekutierung auf ewig verdammt seien oder nicht. Auf der Basis solcher Faktorcn konnten die Gerichte dic von den Plakaten vorgesehenen Strafen verschärfen oder mildern. ${ }^{50}$ Der Vorsitzende des Großen Rates traf dieses Urteil, nachdem ihm cin Fall durch dic Abgeordneten der Stadt Amsterdam vorgelegt worden war. Der Magistrat der Stadt Amsterdam hatte nämlich eine sehr leichte Strafe gegen den Buchverkäufer Jan Seversz. ,den Lahmen' ("dic Croepel”) bei dem ketzerische Literatur gefunden wurde, verhängt. ${ }^{51}$ Der Generalprokurator des holländischen Hofes stimmte dieser Strafe nicht zu und befahl die $\Lambda$ msterdamer Schöffen, die im Ruf standen, in Ketzerdingen viel zu nachlässig vorzugchen, nach Den Haag. Der Generalprokurator

49 Ibid., S. 231-233.

${ }^{50}$ Ibid., S. 205-208, besonders S. 207.

51 Fredericq, Hg., Corpus Inquisitionis, Band 4 (siehe oben, Anm. 1) S. 244; 255; 261; 270-271; 282-283; 289-291; Band 5, S. 193-197; 210-211; 218-221; 309-310. Zum Fall des lahmen Buchverkäufers Jan Seversz. vgl. auch: James D. Tracy, 'Heresy Law and Centralization under Mary of Hungary: Conflict between the Council of Holland and the Central Government over the Enforcement of Charles V's Placards', Archiv für Reformationsgeschichte 73 (1982), 284-307, S. 287-288 und 293294; Den Hollander, De Nederlandse bïbelvertalingen (siehe oben, Anm. 2), S. 103. 
hat zudem damit gedroht, den lahmen Buchhändler nach Den Haag kommen zu lassen. Diese Milde blicb für noch einige Zeit in Holland das Kennzeichen der örtlichen Gerichte. ${ }^{52}$

Anfang 1528 crachtete es die Regentin für nötig, bezüglich der Druckercien, noch eine Verordnung zu crlassen. Am 18. Januar 1528 wurde cin neues Plakat angekündigt, dass sich an den Statthalter und den Rat von Holland richtete. ${ }^{53}$ Dic Regierung zeigte sich zunächst irriticrt, da scine früheren Anordnungen betreffs des Druckes neuer Werke cher lax befolgt würden. Er verlangte, dass seine früheren Ordonanzen neu verkündet und Punkt für Punkt befolgt werden sollten. Konkret bestand er darauf, dass niemand ein Buch drucken dürfe, dessen Vorlage nicht vorher kontrolliert war und dass eine zweite Kontrolle in dem Moment erfolgen müsse, in dem es zum Verkauf angeboten werden solle. Die Dekane von Den Haag und die Dekane von Naaldwijk sollten die Kontrollen durchführen. Außerdem mussten die Drucker ihren Namen und ihr Kennzeichen in all ihren Publikationen anbringen. Geschah dies nicht und wurde das Werk anonym publiziert, dann musste es für beschlagnahmt erklärt werden, und das Gericht konntc nach eigenem Gutdünken dem Drucker cinc Strafe auferlegen. Neben der nachlässigen Befolgung seiner Bcstimmungen betreffs des Druckens ärgerte den Kaiscr auch die Tatsache, dass viele Ordensleute ihren Habit und ihre Ordensgelübde abgelegt hatten, und überall im Land Diskussionen über religiöse Fragen begannen. Gleichfalls am 18. Januar 1528 ordnete dic Regentin Margarethe an, dass die Bestimmungen bezüglich der 7.ensur in Antwerpen und Löwen nochmals verkündet werden mussten. ${ }^{51}$ Am 4. Februar 1528 gab der Stathalter von Holland, Secland und Friesland den Befehl, oben genanntes Plakat in allen Städten Hollands zu verkünden. Durch dieses Plakat wurde auch den Rhetorikern verboten, ihre (Theater-)Spiele weiter aufzuführen, außer sie waren vorab durch die zuständige Obrigkeit geprüft und gutgeheißen.. ${ }^{35}$ Neben Geistlichen, Buchdruckern und Schulmeistern

${ }^{52}$ Goosens, Les Inquisitions, Band 1 (siche oben, Anm. 1), S. 52: “. . cette mesure de clémence, qui entra rapidement dans les moeurs du Conseil de Hollande. Nous ignorons ce qu'il en fut dans les autres conseils provinciaux, mais d'après les sources, les Conseils de Flandre et de Frise allèrent dans le sens de la rigucur". Auch: Fühner, Die Niederlande (siehe oben, $\Lambda \mathrm{nm} .1$ ), S. 180.

i3 Fredericq, Hg., Corpus Inquisitionis, Band 5 (siehe oben, Anm. 1), S. 320-321.

${ }^{5 t}$ Erlaß der Regentin Margarete, 18. Januar 1528, AGR, Papiers d'Étal et de l'Audience, 818, fol. 83v.

${ }^{35}$ Fredericq, Hg., Corpus Inquisitionis, Band 5 (siehe oben, Anm. 1), S. 324-325. 
waren auch die Rhetoriker für ihre Kritik an der Kirche und für ihren freien Umgang mit der Bibel und der Glaubenslehre der Kirche berüchtigt. In Holland hatten dic Rhetoriker genau Mitte der zwanziger Jahre in ihren Spiclen und Liedern ihr Interesse an den neuen Ideen durchscheinen lassen, soweit sie in ihren Augen durch die Schrift selbst gestützt waren. Die Rhetorikervereine in Flandern scheinen frühestens ab der zweiten Hälfte der dreißiger Jahre den Argwohn der Krone bezüglich echter oder vermeintlicher ketzerischer Einflüsse geweckt zu haben. ${ }^{56}$ Am 7. August 1528 verbot der Magistrat von Amstcrdam nochmals den Druckern, etwas zu verlegen ohne das es vorher genehmigt worden war. ${ }^{57}$

Kurzum, Ende der zwanziger Jahre wurde deutlich, dass die Regierung die unkontrollicrte Bibellektüre durch Laien kontrolliert haben wollte. Doch gab es kein Verbot, die Bibel in der Landessprache zu lesen. Allerdings versuchte der Staat, Ausgaben mit Vorreden, Zusammenfassungen und Glossen den Händen der Laien fernzuhalten. Außerdem war die freie Lektüre und Auslegung der Bibel in Konventikeln strikt verboten. So entstand in evangelischen Kreisen das Vorurteil, dass die katholische Kirche Bibclausgaben in der Volkssprache gegenüber feindlich eingestcllt wäre. Diese Haltung passte natürlich in die fortschreitende konfessionelle Polarisierung, in der man der Gegenpartei Motive zuschob, die nicht immer mit der Wirklichkeit übereinstimmten. Für diese Einstellung gibt es eine Reihe von Beispiclen. ${ }^{58}$ Sogar heute noch lebt diese Auffassung, sclbst in wissenschaftlichen Kreisen, fort.

56 $\% u$ den Rhetorikerauführungen als Mittel, die neuen Ideen zu verbreiten: Gary K. Waite, 'Reformers on Stage: Rhetorician Drama and Reformation Propaganda in the Netherlands of Charles V, 1519-1556', Archiv für Reformationsgeschichte 83 (1992), 209-239, 209-220; Decavele, De dageraad (siehe oben, Anm. 4), S. 196-220; Duke, Reformation and Revolt (siehe oben, Anm. 6), S. 90-91 und 106-107. Auch: De Bruin, De Statenbijbel (siehe oben, Anm. 2), S. 127-129; Marnef, Antwerpen (siche oben, Anm. 34), S. 56-58.

i) Fredericq, Hg., Corpus Inquisitionis, Band 5 (siehe oben, Anm. 1), S. 354.

${ }^{50}$ Als David Joris die Ansicht vertrat, dic Autoritäten hätten gewöhnlichen Männern und Frauen verboten, dic Bibel zu lesen, brachte er ein weit verbreitetes Vorurteil zum Audruck, gleichwohl dic Richter bei seinem Prozess 1528 sich Mühe gaben zu verdeutlichen, dass dies streng genommen nicht wahr war. Wohl verboten waren die Konventikeln, wo auf freie Wcisc dic Schrift interpretiert und darum viele Irrlchren verkündet wurden: “... scryuende oic, dat die simpelen verboden zoude zyn te lesen of te spreken van de heylige Scryfte, op lyf en goet, twelck schecn gescreuen te zyn tegen de K.M. of die van zyn Raet, denseluen denoterende tegen de warheit, want sules niet verboden en was, mair zekere tyt geleden by placcaet ende edict gejnterdicecrt ende gejnhibeert dic vergaderinge cnde disputacie 


\section{Der 'Proto-Index' von 1529 und Bibelübersetzungen in die Landessprache}

Die Reformation hörte nicht auf, sich in den Niederlanden zu verbreiten. Darum wurde 1529 ein neues und strengeres Plakat erlassen. Dies geschah am 14. Oktober für das Herzogtum Brabant. Am 25. Oktober wurde dieses Plakat in sciner Urfassung auch für die Grafschaft Flandern verkündet, aber zwei Monate später, am 31. Dezember, durch eine verbesserte Version ersetzt. ${ }^{59}$ Andere Provinzen folgten ihrerseits mit einer Ankündigung. ${ }^{60}$ Das neue Plakat von 1529 markiert

vanden heylegen Scryfte, omme derreuren dair uuyt comende te scuwen; al twelck es smakende groite delicten, wairdich van groite pugnicie" (Fredericq, Hg., Corpus Inquisitionis, Band 5 (siehe oben, Anm. 1), S. 350). Wir verweisen auch auf das Los des Brauers Jan Wytinc, der Mitglied des kleinen reformatorischen Kreises in Brügge, der aus der Stadt verbannt wurde und sich in Antwerpen niedergelassen hatte. Von da aus besuchte er 1528 Frankfurt und bat am 8. Oktober des Jahres den Rat der Stadt schriftlich um die Aufnahme seiner Familie: "Als Begründung für dieses Gesuch führte er an, dass jeder, der in Flandern oder in Brabant über das Evangelium spreche, von der Todesstrafe bedroht sei. Ihm nach war es dort sogar verboten, das Neuc Testament im Haus zu haben oder zu lesen" (Decavele, De dageraad (siche oben, Anm. 4), S. 253).

${ }^{59}$ Die französischsprachige Version für das Herzogtum Brabant ist abgedruckt in Laurent und Lameere, Hg., Recueil des ordonnances, Band 2 (siehe oben, Anm. 1), S. 578-583. In den Fußnoten findet man Hinweise auf den inhaltlich etwas geänderten niederländischen Text, wie er am 31. Dezember 1529 für die Grafschaft Flandern verkündet wurde. Im Rat von Flandern saßen nämlich sehr viele mit erasmianisch-humanistischer Gesinnung, und so gab es auch Protest gegen den allzu strengen Plakatentwurf, wie er von Brüssel vorgelegt worden war. Offiziell hieß es dann auch, dass der Rat sich damit schwer tat, dass die Bestrafung der Übertretungen den Schöffengerichten entzogen wurde. Auf Druck des Landvogtes wurde das Plakat dennoch am 25. Oktober verkündet. Mittlerweile hatten auch die Staaten und Mitglieder Flanderns (d.h. Gent, Brügge, Ypern und das 'Brügger Freiamt') Protest angemeldet, besonders da bestimmte ihrer Privilegien, so die Freistellung von der Konfiszierunge, gestrichen waren. Schließlich wurde am 31. Dezember 1529 auch für Flandern eine neue Version des Plakates verkündet, die allen Beschwerden Rechnung trug und folgende Anpassungen cnthiclt: Bei der Beschlagnahme von Gütern soll den bestehenden Privilegien in bestimmten flämischen Städten Rechnung getragen werden, so die Freistellung der Konfiszierung. Wer jemanden unschuldig als Ketzer anzeigte, soll bestraft werden. Die Ketzerverfolgung sei in Flandern nicht ausschließlich Sache des Rates der Provinz - auch örtliche Gerichte "Schöffengerichten') behielten ihre Zuständigkeit. Eine ausfuhrliche Beschreibung, wic diesc Änderungen zustande kamen, bietet Decavele, De dageraad (siche oben, Anm. 4), S. 32-33; Paul Fredericq, 'Les placards du 14 octobre et du 31 décembre 1529 contre les protestants des Pays-Bas', in Mélanges Godefroid Kurth. Recueil de Mémoires relatifs à l'Histoire, à la Philologie et à l'Archéologie. Band 1: Mémoires historiques (Lüttich, $1908), 255-260$.

60 Für die Grafschaft Artois ist vom Dezember 1530 eine (französischsprachige) Fassung erhalten. Sichc: Lameere, Hg., Recueil des ordonnances, Band 3 (siehe oben, Anm. 1), S. 67-71. 
einen neuen und wichtigen Schritt in Richtung eines Index verbotener Bücher und kann darum ein 'Proto-Index' genannt werden. Die Liste verbotener 'reformatorischer' Vcrfasser auf den Spuren Luthers wurde um Namen wie John Wyclif, Jan Hus, Marsilius von Padua, Ulrich Zwingli, Otto Brunfels, Johann von Goch (Gortianus, Puperius $^{6 !}$ und andere erweitert.

Zudem wurde das Verbot von Bibelausgaben in der Landessprache, dic Glossen, Anmorkungen und Einleitungen mit lutherischer Lehre enthielten, wiederholt. ${ }^{62}$ Mchr noch, ein explizites Verbot wurde für

${ }^{61}$ Auf dem Plakat stand "Johannes Puperii et Gorcianus" (Laurent und Lameere, Hg., Recueil des ordonnances, Band 2 (siche oben, Anm. 1), S. 579). Dies betraf jedoch die gleiche Person, nämlich Johann Pupper von Goch. Sein Name wird in verschiedenen Indizes große Verwirrung stiften (Reusch, Der Index der verbotenen Bücher, Band 1 (siehe oben, Anm. 1), S. 106-107.)

62 Ubrigens passierte in der Zeit zwischen dem Erscheinen des ursprünglichen Plakates am 14. Oktober 1529 und dessen Verkündigung in Flandern am 31. Dczcmber 1529 im Dorf Ertvelde eine bemerkenswerte Geschichte. Das Gebiet in Nordflandern, auf der Linie von Antwerpen über Gent nach Brügge, wurde von vielen Buchhändlern aus Antwerpen bereist, und so waren dort auch früh verdächtige Schriften im Umlauf. Martin de Coninck, der Vogt von Assenede, begann sich spätestens seit 1527 als eifriger Verfechter lutherischer Ideen zu zeigen. Ende 1529 hat ihm der Rat von Flandern den Prozess gemacht. 7u seiner Verteidigung führte de Coninck an, "dass er scine Überzcugung aus cinem flämischen Neuen Testament gewonnen habe. Er erwähnte allerdings nicht, dass dieses Buch 'prefacien, prologien ende apostillen' enthielt, 'inhoudende suspecte lecringhen ende doctrinen, ende scandaleuze figuren ende alzo verboden ende gheinterdicert byde placaten 's kcysers ons ghcduchs hecren" (Decavele, De dageraad (siehe oben, Anm. 4), S. 265; unsere Übersetzung). Dic Information, dass flämische Neue Testament habe nicht nur ketzerische Glossen und Vorreden enthalten, sondern auch "skandalöse Bilder" ("scandaleuze figuren") ist zumindest interessant. Aus dieser Zcit sind nur zwei niederländische Neue T'estamente bekannt, die in der Apokalypsc Bilder mit unverkennbar anti-römischer Tendenz zeigten: das berüchtigte Neuc Testament Hans (1) van Ruremunds von 1525 und das des Kölner Druckers Hiero Fuchs vom selben Jahr. Die Sache ist noch interessanter, da 1526 in der Kirche von Ertvelde ein Glasmalereifenster angebracht wurde mit "scandaleuse figure d'aucunes ymages en dérision de Dieu et de ses apostres et de la foi chréticnnc" (Ibid., S. 264). Decavele vermutet bei letzterem die Hand des Vogtes de Coninck im Spicl. Ob es zwischen dem Glasmalereifenster und den "scandaleuze figuren" aus dem Neuen Testament, dass der Vogt besaß, cine Beziehung gibt, bleibt eine schwer zu beantwortende Frage. Jedenfalls: "Das Buch wurde auf dem Vecrleplatz in Gent offentlich verbrannt" (Ibid., S. 265, Anm. 156; unsere Ubersetzung). De Coninck, der zur Besinnung gekommen war, wurde durch den Rat von Flandern verurteilt, auch offentlich seinen Irrlehren abzuschwören: "Dies tat er in Gent am 11. Dezember 1529 und am darauf folgenden Sonntag vor und während des Hochamtes in Ertvelde. Zusätzlich hatte der Vogt $24 \mathrm{fl}$. an die Kirche zu bezahlen, 'ter decoratie van de cyboric van den helighen sacramentc', und $120 \mathrm{fl}$. Buße. Am Schluss hat man ihn seines Amtes enthoben und für unfähig crklärt, in Flandern jemals wieder ein offentliches Amt auszuüben" (Ibid,, S. 265; unsere Ubersetzung). 
Ausgaben des Neuen Testamentes dreier Verleger verhängt: Adriaen van Berghen, Christoffel van Ruremund und der etwas mysteriöse "Johannes Zel". Der einzige bekannte Johannes Zcll ist der Sohn des ersten bekannten Kölner Druckers Ulrich Zell. Dieser Johannes Zell hat niemals den Druckerberuf seines Vaters übernommen, ${ }^{63}$ so dass sich die Löwener 'Theologen hier vielleicht vertan haben. In der Literatur wird allgemein angenommen, dass die Thcologen eigentlich Jan (1) van Ghelen meinten, vor allem, weil auf ciner Leidener Fassung des Plakates, datiert auf Januar 1530, der Name Johannes Zell ersetzt wurde durch diesen Jan (1) van Ghelen. Genauer gesagt sollen die Theologen seine Ausgabe von 1526 im Visicr gehabt haben. ${ }^{6+}$ Als zusätzliches Argument für die Identifikation mit van Ghelen wird auf dic Iöwener Indizes von 1546, 1550 und 1556 verwiesen. Diese verbicten u.a. eine Ausgabe des Neuen Testamentes, von der kein Name des Herausgebers, kein Ort und kein Datum der Veröffentlichung genannt wird. Der angegebenc Titel passt zur niederländischen Edition van Ghelens von 1526..$^{65}$ Gegen die Identifikation mit

${ }_{63}$ Ulrich \%ell aus Hanau (bei Mainz) ist der erste bekannte. Drucker aus Köln. Sein erstes datierbares Werk stammt von 1466 . Vier Jahrzehnte lang cntfaltete er cinc intensive Drucktätigkeit in Köln. 1507, ungefähr siebzig Jahırc alt, starb er. Ulrich Zell hatte cinen Sohn, Johannes /ell. Dieser hat wohl dic Werkstatt seines Vaters nicht weitcrgeführt. Die' Druckausrüstung des Vaters Ulrich Zell hat höchstwahrscheinlich Laurenz. Borncmann aus Münster in Westfalen übernommen. Vgl.: Johan Jacob Merlo und Otto Zarctzky, Ulrich Zell. Koelns erster Drucker [Vcröffentlichungen der Stadtbibliothek in Köln 3」 (Köln, 1900), S. 1-38; Ernst Voulliéme, Der Buchdruck Kölns bis zum Ende des Irünfzehnten fahrhunderts [Publikationen der Gesellschaft für Rheinische: Geschichtskunde 24] (Bonn, 1903; anast. Düsseldorf, 1978), S. II-XII; Severin Corsten, 'Ulrich '/ells deutschsprachige Drucke', in Studien zum Kölner Frühdruck. Gesammelle Beiträge 1955-1985, Hg. Severin Corsten, Kölner Arbeiten zum Bibliothcks- und Dokumentationswesen 7 (Köln, 1985), S. 195-207; Severin Corsten, 'Ulrich Zell als Geschäftsmann', in Studien zum Köhner Frühdruck, Hg. Corsten, S. 208-228.

${ }^{64}$ Es handelt sich um das Plakat, dass am 8. Januar 1530 in Leiden erlassen wurde und das eine Auslegung des kaiserlichen Ediktes von 1529 z.1. sein scheint. Das Leidener Plakat hat für lutherische Bücher ein Verbot erlassen. Genannt wurden u.a. die Nusgaben des Neuen Testamentes mit "versatiën oft annotacien", herausgegeben von drei Antwcrpener Druckern: Adriaen van Berghen, Christoffel van Rurcmund und Jan (1) van Ghelen. Dies könnte belegen, dass mit "Johannes Zel" tatsächlich Jan (1) van Ghelen gemeint war. Das kaiserliche Plakat von 1529 wurde noch anders interpretiert: die Ausgaben von 1525-1526 der drei genannten Drucker, dic keine Vorreden oder Glossen enthielten, wurden durch das Leidener Plakat ausdrücklich zugelassen. Vgl. L aurentius Knappert, 'De Index I.ibrorum Prohibitorum te Leiden in 1530', Tijdschrift zoor Boek-en Bibliotheekwezen 4 (1906), 224-227.

6.5 Der Titel in den Indizes stimmt aber genau mit dem einer Ausgabe des Kölner Druckers Hicro Fuchs von 1525 überein. Das zweite Argument muss darum mit äußerster Vorsicht benutzt werden, vor allem deshalb, weil der erste Löwener Index 
van Ghelen spricht, dass nirgends bekannt ist, dieser Hcrausgeber habe 1529 Schwierigkeiten mit den Gerichten gehabt. Mehr noch, es gibt keine Hinweisc, dass er jemals in seinem Leben mit der Justiz in Berührung gekommen ist. Darum favorisieren wir, dic Möglichkeit offen zu lassen, dass mit Johannes Zel Hans (1) van Ruremund gemeint sei, der vermeintliche Bruder von Christoffel. In diesem Fall würden die drei genannten Drucker drei oder gar vier Merkmale gemcinsam haben. Es handelt sich erstens um Antwerpener Drucker. Zweitens hatten Adriaen van Berghen, ${ }^{66}$ Christoffel van Ruremund ${ }^{67}$

erst siebzehn Jahre nach dem Plakat von 1529 erschien. Siche auch: De Bruin, De Statenbijbel (siehe oben, Anm. 2), S. 84; 130; Den Hollander, De Nederlandse bijbelvertalingen (siehe oben, Anm. 2), S. 50-51.

tis Der Antwerpener Drucker Adriaen van Berghen hatte bis 1.522 gut kirchliche: Werke hergestellt. $1522 \mathrm{kam}$ die Wende, und er verlegte sich auf die Herausgabe reformatorischer Literatur. Dafür wurde er sofort von den Gerichten belangt. Das hindertc ihn nicht, 1523 als erster Drucker in den Nicderlanden eine niederländische Übersetzung des Neuen Testaments auf den Markt zu bringen, die sich mindestens teilweise (für die Evangelien, die Apostelgeschichte und die Offenbarung) auf das noch junge Septembertestament Luthers stützte. Insgesamt sollte er fünf niederländische Ausgaben des Neuen Testamentes (oder T'eile davon) herausgeben, die alle mehr oder weniger auf dic lutherübersetzung zurückgingen: eine 1523, zwei 1524, eine 1525 und einc 1533. Van Berghen, der in Antwerpen verschicdene Male mit der Justiz wegen Publikation unerlaubter Werke in Berührung kam, wurde 1536 zu einer Wallfahrt nach Nicosia verurteilt. Stattdessen wich er aber nach Holland aus, wo er in diversen Städten wohnte. 1542 wurde ein Paket verbotener Bücher in scinem Haus in Delft entdeckt, und cr wurde im Auftrag des Gencralprokurators des Hofes von Holland enthauptet (Anne Rouzet, Hg., Dictionnaire des imprimeurs, libraires et éditeurs des $\mathrm{XV}^{\text {e et }} \mathrm{XVI^{c }}$ siècles dans les limites géographiques de la Belgique actuelle [Collection du Centre National de l'Archéologie et de l'Histoire du Livre - Publi(ations 3] (Nieuwkoop, 1975), S. 12-14; De Bruin, De Statenbijbel (siehe oben, Anm. 2), S. 84-85; Den Hollander, De Nederlandse bijbelvertalingen (siehe oben, Anm. 2), S. 42$49 ; 218 ; 292-294)$.

${ }_{6 i}$ Der Antwerpener Drucker Christoffel van Ruremund (oder van Eindhovenbij-Roermond) gab drei niederländische Ausgaben des Neuen Testamentes heraus, die alle auf dic cine oder andere Weise auf den luthertext zurückgingen: 1525, 1526 und 1528. 1525 gab er auch eine niederländische Übersetzung des Makkabäerbuches heraus, die auf der Vulgata basierte. Christoffel van Ruremund druckte auch englische reformatorische Übersetzungen des Neuen Testaments, vielleicht TyndaleAusgaben. Dazu reiste er mehrere Male nach England. Der englische Handelsattaché in Antwerpen warnte den englischen Kardinal Wolsey ab 1526 regelmäßig vor dem Import verbotener Litcratur aus den Niederlanden. Er berichtete auch von den gerichtlichen Mal3nahmen, die im Herbst 1526 und Frühjahr 1527 in Antwerpen ergriffen wurden, um gegen die Verbreitung des Neuen Testamentes in England vorzugehen. Dabei namnte der Handelsattaché auch den Namen Christoffel van Ruremund. Trotzdem exportierte letzterer weiterhin verbotene Bücher über den Ärmelkanal. Der Antwerpener Drucker wurde während eines Aufenthaltes in England, 1531, gefangen genommen und in Westminster eingesperrt. Dort ist er verstorben (Rouzet, Hg., Dictionnaire (siehe oben, Anm. 66), S. 193-194; De Bruin, De Statenbijbel 
und Hans (1) van Ruremund ${ }^{68}$ bereits 1525 gewagt, eine niederländische Ausgabe der Heiligen Schrift mitsamt Vorreden und/oder Randbemcrkungen zu publizieren, die auf die eine oder andere Weise auf die Lutherausgabe zurückgingen. Jan (1) van Ghelen folgte 1526 mit eincr Ausgabe, die stark vom bereits erwähnten Deventer Neuen Testament Albert Pafraets von 1525 inspiriert war. ${ }^{69}$ Auffällig ist ferncr, dass die betroffenen Drucker diese Glossen und Prologe nicht mchr auf ihren 'Titelseiten ankündigten, wie das zwischen 1522 und Anfang 1524 durchaus üblich war. Vielleicht hatten sie erkannt, dass eine derartige Ankündigung sie für Maßnahmen der Inquisition besonders angreifbar machte. Ihre Vorsicht nutzte den dreien nichts: Die reformatorischen Publikationen van Berghens, Christoffel und Hans

(siche oben, Anm. 2), S. 84-85; Den Hollander, De Nederlandse bijbelvertalingen (siche oben, Anm. 2), S. 67-71; 221;311-313).

${ }_{68}$ Über Hans (1) van Ruremund ist wenig bekannt. In der ersten Jahreshälfte 1525 druckte er eine niederländische Ausgabe des Alten Testamentes in vier Bänden für Peter Kaetz. In der zweiten Hälfte desselben Jahres brachte Hans eine niederländische Ausgabe des Neuen 'Testamentes auf den Markt. Im folgende Jahr bekam er Probleme mit der Justiz. Diese würde ihn danach nicht mehr in Ruhe lassen. Wegen des Druckes lutherischer Bücher wurde er Oktober 1526 durch den Antwerpener Schultheiß Claes van Lyere zu einer Wallfahrt zum "Heiligen Blut" in Wilsnach, Preussen, verurteilt (Fredericq, Hg., Corpus Inquisitionis, Band 5 (siche: oben, Anm. 1), S. 154-155). Um wclche Bücher es genau ging, wurde nicht gesagt. So bleibt die Möglichkeit, dass es sich um seine lutherische Ausgabe des Neuen Testaments handelte. Hans (1) van Ruremund war wie sein Bruder (?) auch auf dem englischen Markt aktiv, für den er u.a. Neue Testamente in der 'Tyndale Übersetzung druckte. Januar 1527 verbot Claes van Lyere, in Antwerpen englische Neue Testamente zu besitzen. P. Fredericq meint, dass der Antwerpener Schultheiß, wie einige Monate zuvor, Hans (1) van Ruremund im Blick hatte (Ibid., S. 184-185). Während seiner 'Geschäftsreise' nach England, 1528, wurde Hans (1) van Rurcmund verhaftet und in London eingesperrt. Scitdem hat man nichts mehr von ihm gehört, was das Schlimmste vermuten lässt. Etliche Autoren gehen aber davon aus, dass Hans (I) van Ruremund wieder frei kam, nach Antwerpen zurückkehrte, aber bald wieder nach England ging, wo er unter dem Namen John Holibusche weiterarbeitete (Rouzet, Hg., Dictionnaire (siehe oben, Anm. 66), S. 194-195; De Bruin, De Statenbijbel (siehe oben, Anm. 2), S. 84-85; Den Hollander, De Nederlandse bijbeluertalingen (siehe oben, Anm. 2), S. 66-68; 221-222 und 318-320). Siehe jetzt auch den Beitrag von Herbert Migsch, 'Die Jeremia-Übersetzung in der Ruremundebibel (1525): Eine nach der Complutenser Vulgata und der ersten Rabbinerbibel revidierte Übersetzung aus der Delfter Bibel (1477), in dem vorliegenden Band.

69 Von Jan (1) van Ghelen sind sechs niederländische Ausgaben des Ncuen Testamentes bekannt: 1524, 1525, zwei 1526, 1528 und 1530. Fünf davon gingen auf die eine oder andere Weise auf dic Lutherübersetzung zurück. Es gibt keine Anweisungen, dass er mit der Justiz Probleme hatte. Er ist 1549 oder Anfang 1550 gestorben (Rouzet, Hg, Dictionnaire (siehe oben, Anm. 66), S. 71; De Bruin, De Statenbijbel (siehe oben, Anm. 2), S. 84; Den Hollander, De Nederlandse bijbelvertalingen (siche oben, $\Lambda$ nm. 2), S. 49-51;224; 324-325). 
(1) van Ruremunds zogen in einem sehr frühen Stadium die Aufmerksamkeit der Justiz auf sich. Zu van Ghelen ist nicht bekannt, dass er jemals mit der Inquisition Probleme bekommen hat, was bereits gesagt wurde und ein Argument darstellt, ihn nicht mit dem Johannes Zel des Plakates von 1529 zu identifizieren. So ist es nicht unwahrscheinlich, dass das Plakat von 1529 die Namen dreier Drucker und Herausgeber zusammenbringt, die in diesem Moment mit ihrer Lutherübersetzung und entsprechenden Anmerkungen das Augenmerk der Inquisition auf sich gezogen haben. Verschiedene Löwener Theologen hatten mit der Inquisition zu tun, und dass ist vielleicht die Erklärung, warum das Plakat anfügte, dass dic drei genannten Ausgaben voll lutherischer Ketzereien seien und darum durch die theologische Fakultät Löwen verurteilt wurden. ${ }^{70}$ Der Vollständigkcit halber fügen wir an, dass die Ausgabe von Hans (1) van Ruremund selbst dic sciner Kollegen an 'Bösartigkeit' übertraf. Als einer der wenigen Herausgeber in den Niederlanden hatte er es gewagt, in den berühmten Illustrationen der Apokalypse die Bestie aus dem Abgrund (Apk 11,7; von Luther mit dem Antichrist identifiziert), die Bcstic der Apokalypsc 16,10-13 und die Hure Babylon (Apk 17,1-6) mit der päpstlichen Tiara als Kopfbedeckung abzubilden. Diese Illustrationen für die Apokalypse lehnten sich an die 21 Bilder an, die Hans Holbein der Jüngere für die 1523 in Basel bei Thomas Wolffs crschienene Lutherbibel angefertigt hatte. Nur der Kölner Drucker Hiero Fuchs hat in seiner niederländischen C̈bersetzung des Neuen Testamentes auch die Tiara aufgenommen. ${ }^{71}$ Dass die Löwener Theologen diese Kölner Ausgabe ungenauerweise einem anderen Sproß einer Druckerfamilic dicser Stadt zugeschrieben haben, "Johannes Zel", ist keinesfalls auszuschließcn. Auch M.E. Kronenberg rechnet damit, dass die Angabe "Johannes Zel" letztendlich auf einc in Köln erschienene Ausgabe verweist, ohne eine Verbindung mit Hiero Fuchs zu sehen ${ }^{72}$ Dazu kommt obiges Argument, dass die Löwener Indizes

${ }^{70}$ In der französischen Version des Plakates für das Herzogtum Brabant hic $\beta$ es: “... plains d'hérésies luthéranes ou autres, et pour telz réprouvez et condempnez par la faculté des théologiens de l'université de Louvain" (Laurent und Lameere, Hg., Recueil des ordonnances, Band 2 (siehe oben, Anm. 1), S. 579).

${ }_{71}$ Bart Rosier, De Nederlandse bijbelillustraties in de zestiende eeuw. De illustraties in de bijbels gedrukt in de Nederlanden en in de Nederlandstalige bijbels gedrukt in het buitenland van 1522 lot 1.599, Band 2 (Amstcrdam, 1992), S. 5-6; 48-49; 128-130.

${ }^{72}$ Wouter Nijhoff und Maria Elizabeth Kronenberg, Nederlandsche Bibliographie van 1500 tot 1540, Band 3 Einleitung (s Gravenhage, 1942), S. 21 nr. 0154. 
von 1546, 1550 und 1556 eine Ausgabe des Neuen Testamentes verbieten, ohne den Namen des Druckers/Herausgebers, Ort oder Datum zu nennen, aber deren Titelangabe übereinstimmt mit der Edition des Kölner Druckers Hiero Fuchs von 1525 (und der von Jan (1) van Ghelen von 1526).

Zum andern fällt auf, dass Drucker/Herausgeber, die außerhalb des Löwen-Brabanter Bercichs operierten, auf dem Ketzerplakat von 1529 nicht namentlich genannt wurden. ${ }^{73}$ Dies ist der Fall für einige nordniederländische Ausgaben, u.a. das gerade besprochene Neue Testament, das Doen Pietersoen 1523 in Amsterdam herausgegeben hat. Es basiert als erstes vollständig auf der Lutherübersetzung und hatte außerdem die Anmerkungen des Reformators aus Wittenberg übernommen. Mehr noch, Doen Pietersoen hat die Glossen und/oder Prologe im Titel angekündigt. ${ }^{74}$ Der Amsterdamer Verleger hatte übrigens mit seiner früheren Edition des Matthäusevangeliums von Johan Pelts bereits die Gerichte auf sich aufmerksam gemacht. Die oben besprochene Ausgabe, die Albert Pafraet 1525 in Deventer herausbrachte und dic auf der Lutherübersetzung basierte und mit Luthers Anmerkungen und Vorreden versehen war, nannte das Plakat ebenfalls nicht. Pafraet war in dieser Periode sogar einer der wenigen, der seine Glossen und Vorreden auf der Titelseite ankündigen durfte. Deventer lag an einem Handelswegeknotenpunkt und bildete mit seiner Kapitelsschule und aktivem Druckereiwesen ein geistliches Zentrum. In der Stadt herrschte ein tolerantes Klima in Beziehung auf reformatorisch gesinnte Leutc. 1525 stand es noch unter der Herrschaft des Bischofs von Utrecht und kam erst 1528 unter die Habsburger. Trotzdem hielt Pafraet es für ratsam, sein Werk anonym und mit der Scheinadresse 'Basel' zu veröffentlichen, ein Vorgehen, das Drucker öfter anwandten, um außer Reichweite der Inquisition zu blciben. Zweifelhaft ist, ob die angeführten nordniederländischen

${ }^{73}$ Die Hypothese, das Plakat von 1529 spiegele eine 'Löwener Liste' wicder, wurde bereits 1883 von F.H. Reuss vorgebracht. Der Autor ging oflenbar davon aus, dass die Universität eine eigene interne Zensur verfolgte und ihren Professoren und Studenten (und auch den gebildeten Einwohnern der Stadt) regelmäßig eine Büchcrliste, deren Lektüre verboten war, erstellte. Karl V. habe dann eine solche interne Brabant-Löwener Liste auf seinem Plakat von 1529 aufgenommen und damit größere Tragweite verlichen. Ähnlich soll es beim Plakat von 1540 gewesen sein (Reusch, Der Index der verbotenen Bücher (siehe oben, Anm. l), S. 113).

${ }^{74}$ De Bruin, De Statenbijbel (siehe oben, Anm. 2), S. 79; 84; Den Hollander, De Nederlandse bijbeluertalingen (siehe oben, Anm. 2), S. 40; 214-215; 274-279. 
Ausgaben in Löwen bekannt waren. Zwar druckten Jan (1) van Ghelen $^{75}$ und Doen Pictersoen ${ }^{76} 1526$ noch cinc Ausgabe, die sehr auf Pafraet beruhte. Obgleich diese Ausgaben nicht ausdrücklich auf der Löwen-Brabanter Liste aufgeführt wurde, so kann doch kein Zweifel daran bestehen, dass sie verboten waren. Im Plakat war ja eine allgemeiner formulierte Zensur enthalten, die alle Bibelausgaben auf Niederländisch oder Französisch betraf, die Einleitungen oder Anmerkungen mit reformatorischen Irrlehren cnthiclten. ${ }^{77}$ Bibelübersetzungen ohne paratextuclle Elemente reformatorischen Einschlags wurden nicht ausdrücklich verboten. Auch 1529 war von einem direkten Bibelverbot keine Rede. ${ }^{78}$ Übrigens fielen auch alle Werke der letzten zehn Jahre (also seit 1519-1520), die ohnc Angabe von Verfasser oder Drucker, Ort oder Zeit erschienen waren, unter das Bücherverbot.

Jeder, der dergleichen reformatorische Schriften, verbotene Bibelübersetzungen und ebensolche Kommentare oder anonyme Schriften in seinem Besitz hielt, bekam vierzig Tage Zeit, sie bei den zuständigen Instanzen abzuliefern, um sie verbrennen zu lassen. Diese Leute konnten auf Begnadigung zählen. Wer die verbotene Lektüre nicht abgab und darum unmissverständlich in seiner ketzerischen Gesinnung verharrte, wurde mit dem Tod bestraft ("confiscation de leur corps") und mit der Beschlagnahmung seiner Güter ("confiscation de leurs biens"). ${ }^{79}$ Männer sollten enthauptet und Frauen lebend begraben werden. Rückfällige, also solche, die zunächst ihrer ketzerischen

7. De Bruin, De Statenbijbel (siehe oben, Anm. 2), S. 90; Den Hollander, De Nederlandse bijbelverlalingen (siehe oben, Anm. 2), S. 224; 324-325.

${ }^{76}$ De Bruin, De Statenbijbel (siehe oben, Anm. 2), S. 90; Den Hollander, De Nederlandse bijbelverialingen (siehe oben, Anm. 2), S. 42; 225; 330-332.

77 "... ny semblablement le Nouveau Testament, ny les Evangilles, epistres, prophécies, ne autres quelcuncques livres en franchois ou thiois, ayans préfaces ou prologues, appostilles ou glosses, contenans ou sentans aucun doctrine ou crreur, ou aucunement déroguans, répugnans ou contraires à la foy chrestienne, aux sacramens, aux commandemens de Dieu et de l'Eglise ou la doctrine d'icelle" (Laurent und Lameere, Hg., Recueil des ordonnances, Band 2 (siehe oben, Anm. 1), S. 579).

${ }^{78}$ Die Angabe J. Fühners in Bezug auf das Plakat von 1529 scheint etwas zu undifferenzicrt: "Die seit 1521 erlassenen Zensurbestimmungen wurden wiederholt und durch das Verbot, die Evangelien oder sie kommentierende Schriften aus dem Lateinischen ins Französische, Niederländische oder eine andere Volkssprache zu übersetzen beziehungsweise Übersetzungen zu drucken, crgänzt" (Fühner, Die Niederlande (siehe oben, Anm. 1), S. 183).

${ }^{79}$ Wie bereits erwähnt, vermochten sich der Rat und die Staaten von Flandern mit Verweis auf alte Privilegien Ausnahmen zu sichern für Yper, Brügge, Gent und das Brügger Freiambt, wo sich eine Konfiszierung auf 60 p. par. beschränkte (Decavele, De dageraad (siehe oben, Anm. 4), S. 44-45). 
Gesinnung abgeschworen hatten, aber danach wieder crtappt wurden, sollten lebendig verbrannt werden. Während das Plakat von 1526 noch die (ewige) Verbannung als Strafe für den Besitz von Ketzerschriften empfahl, so wurde 1529 die Strenge der niederländischen und französischen Version des Ediktes von Worm voll angewandt: die Todesstrafe wurde nun für die Übertretung des Bücherverbotes eingeführt. So wird also deutlich, dass nicht allein die Zensur, sondern auch die Strafen des Plakates von 1529 viel strikter waren als die drei Jahre zuvor. ${ }^{80}$ Und cinc noch grundsätzlichere Entwicklung begann sich abzuzeichnen: dic kanonisch festgelegte Straftat 'Ketzerei' und die Übertretung der Ketzerplakate gingen mehr und mehr Hand in Hand. Konkret schien man den bloßen Besitz verbotener Bibeln und anderer verdächtiger Literatur als unwiderlegbaren Beweis für ketzerische Gesinnung zu betrachteten, und diese musste folglich mit dem Tod bestraft werden. Vor 1529 war dies noch nicht der Fall und es wurde offensichtlich akzeptiert, dass auch menschliche Motive eine Rolle spielen konnten, wenn jemand lutherische Schriften las, wie z.B. ungesunde Neugierde, Einfluss von Freundeskreisen ... ${ }^{8 !}$ Dic zunehmende Strenge ist auch mit dem Umstand zu erklären, dass der Staat dic weitere Verbreitung reformatorischer Ideen nur mühsam einschränken konntc. Karl V. wollte entschieden die Leitung der Ketzerbekämpfung in den Niederlanden an sich ziehen. ${ }^{82}$

Es ging um noch mehr. Da nun Bibeln in der Landessprache, eventuell mit Glossen, Vorreden und Zusammenfassungen, zur Verfügung standen, konnten Laien darin lesen und darüber diskutieren. Schon das Plakat von 1526 hat als eine der Ursachen für die Verbreitung der Ketzereien genau diesen Umstand angeführt, dass gewöhnliche, ungebildete Laien, von Luther dazu gedrängt, anfingen, die Schrift zu kommentieren. Derselbe Gedanke kehrt wieder im Plakat von 1529 und nochmals wurde verboten, dass man über dic Schrift diskutiere, ohne ein durch eine bekannte und angesehene Universität anerkannter Theologe zu sein. ${ }^{83}$ Daraus können wir den

\footnotetext{
S. 182

${ }_{81}$ Duke, Refomnation and Revolt (siche oben, Anm. 6), S. 158; auch 161-162; Goosens, Les inquisitions, Band 1 (siehe oben, Anm. 1), S. 53.

$8: 2$ Goosens, Les inquisitions, Band 1 (siehe oben, Anm. 1), S. 177.

${ }_{83}$ "En outre plus, que nul, de quelque estat qu'il soit, ne s'avance communiquer ou disputer de la sainte Escripture, mesmement en matière doubtive, et dont scroit difficulté, s'ilz ne feussent théologiens bien renommez et approuvez par université
} 
Versuch der Löwener magistri ersehen, die Kontrolle über die Thcologie in den Niederlanden in der Hand zu behalten. Dic Löwener Theologen haben freilich noch auf eine andere Weise begonnen, die Initiative an sich zu ziehen. Statt erschienene Bibelübersetzungen zu verfolgen, wollten sie diese schon vorab auf ihre Rechtgläubigkeit hin prüfen. Ein Ansatz in diese Richtung steckte in der Anerkennung eines "cum gratia et privilegio" für die Vorstermanbibel von 1528 durch u.a. den Löwener Theologen Nicolas Coppin. Diese Praxis vorausgehender Zensur für Bibclübersctzungen in der Volkssprache wurdc dann auch offiziell durch das Plakat von 1529 vorgeschrieben: Fortan war es verboten, ohne vorausgehende Zulassung die Bibel auf Niederländisch, Französisch oder eine anderc Sprache außer Latein zu übersetzen und zu publizicren. Es war auch verboten, solche Übersetzungen aus dem Ausland einzuführen. Nur Editionen, dic über die ausdrückliche Genehmigung der zuständigen Autoritäten verfügten, konnten fortan auf den Markt gebracht werden. Wer dieses Publikationsverbot nicht kontrollierter und nicht genehmigter Bibelübersetzungen übertrat, erhiclt zwar nicht die Todesstrafe, aber wird doch cinc schwere Geldbuße von 500 goldenen carolus auferlegt. ${ }^{8+}$ Allerdings benötigten alle neuen Bücher, die gedruckt oder aus dem Ausland eingeführt werden sollten, eine vorherige Zulassung durch die Obrigkeit. Sobald cin Buch über ein religiöses Thema handelte, musste der Ortsordinarius oder sein Bevollmächtigter die Genehmigung erteilen. Für jedes andere Buch hatte die weltliche Autorität dies zu tun, nach Rücksprache mit dem Ordinarius oder mit dessen Vertreter. Wer ohne offizielle Erlaubnis dennoch ein Buch publizierte, den traf cine Geldbuße von 500 goldenen carolus.

Das Plakat von 1529 sah zudem eine Reihe von Sanktionen für Wirte und Privatpersonen vor, die Ketzern Schutz und Unterschlupf

fameuse" (Laurent und Lameere, Hg., Recueil des ordonnances, Band 2 (siche oben, Anm. 1), S. 580).

Bt "Que nul, de quelconques nacion, sexe, estat ou condition, ne présume ou s'avance doresnavant translater, escripre ou imprimer, planer ou lyer en nostre dict romant pays de Brabant, aucuns livres, coyeres ou quelconques dictiers de la sainte Escripture, en franchois ou thiois, ne en autre langaige que latin, ne aussi le faire faire; ne de apporter ou faire apporter en nostredict pays lesdicts livres ou aulcun d'iceulx qui seroient translatez, escriptz ou imprimez cn aultre pays, sans le congié préalablement de l'ordinaire ou de nosdicts chancellier et gens de nostredict conseil oudict pays et leur approbation desdicts livres, coyers ou escriptures: à paine $\mathrm{dc}$ cincq cent florins karolus d'or de nostre coing, à incourir par tous ceulx et chacun d'eulx qui feroient le contraire, et chascune fois qu'ils le feroient" (Laurent und Lameere, Hg., Recueil des ordonnances, Band 2 (siehe oben, Anm. 1), S. 580-581). 
zukommen ließen. Umgekehrt stellte man für diejenigen eine finanzielle Belohnung in Aussicht, die Ketzer der Obrigkeit anzeigten oder verrieten. ${ }^{85}$ Man sah auch Regelungen vor, die allzu laxe Magistrate und Gerichtsbeamte zu mehr Eifer bei der Ketzerverfolgung bewcgen sollten, was nochmals belegt, dass die strenge Religionspolitik der kaiserlichen Regierung von der Basis nicht mit gerade großer Begeisterung angenommen wurde. Wer wegen Verdachtes der Ketzerci mit den Gerichten zu tun bekommen hatte, durfte kein öffentliches Amt mehr bekleiden usw. Wie das ursprüngliche Plakat von 1529 zeigte, war es das Ziel, die Ketzerverfolgung künftig den Gerichten vor Ort, die nach Gewohnheitsrecht handelten, zu entzichen und ausschließlich (zwei speziellen Kommissaren in) den Provinzgerichten zu reservieren, wofür es dem Rat und den Staten von Flandern glang, eine Ausnahme zu erhalten. ${ }^{86}$ Im Gegensatz zu dem breiten Raum, der zuvor den örtlichen Gerichten gegeben war, für jeden Einzelfall die Strafen an dic jeweiligen Umstände anzupassen, wurde ab 1529 von den Gerichten offensichtlich eine strikte Anwendung der Bestimmungen des Plakates gefordert. ${ }^{87}$ Das Plakat vom 14. Oktober und das vom 31. Dezember 1529 bildeten über mehrere Jahre die Grundlage für den Kampl gegen religiöse Dissidenten und insbesondere für die Bibelpolitik. ${ }^{88}$ Am 8. Januar 1530 crschicn eine Erläuterung zum Plakat von 1529, wodurch die Verbote noch konkreter umschrieben wurden. Dies betraf allerdings keine Bibelausgaben. ${ }^{89}$

${ }^{85}$ In der Fassung für die Grafschaft Flandern vom 31. Dezember 1529 wurde, wie erwähnt, die Klausel eingebaut, dass die Ankläger Unschuldiger bestraft werden sollten. Die Prüfung der Glaubwürdigkeit von Anzeigen oder Zeugen während der Voruntersuchung, die sogenannte informatie precedente, wurde für den Prozess als wesentlich eingestuft. Erst wenn dic Begründbarkeit der Anklage deutlich war, konnte man zur Verhaftung des Verdächtigen schreiten. Vgl. Duke, Reformation and Revolt (siehe oben, Anm. 6), S. 159.

${ }^{85}$ Die Ketzcrverfolgung ging nicht ausschließlich an den Provinzrat: Die nach Gewohnheitsrecht vorgehenden örllichen Gerichte scheinen ihre Zuständigkeit behalten zu haben, wenn auch unter der Aufsicht des Rates von Flandern (Decavele, De dageraad (siehe oben, Anm. 4), S. 37).

${ }^{87}$ Laurent und Lameere, Hg., Recueil des ordonnances, Band 2 (siche oben, Anm. 1), S. 582-583; Goosens, Les inquisitions, Band 1 (siehe oben, Anm. 1), S. 73.

${ }_{88}$ "Die Gesetzgebung gegen die Neugläubigen in den Niederlanden vollzog somit eine entscheidende Wende, denn alle späteren Modifikationen der Gesetze dienten nur noch der Präzisierung der juristischen Verfahrenswcisen oder der Verschärfung der Strafen auf der Grundlage der in der Ordonnanz vom 14. Oktober 1529 aufgestellten Prinzipien" (Fühner, Die Niederlande (siehe oben, Anm. 1), S. 187).

${ }^{89}$ Reusch, Der Index der verbotenen Bücher (siehe oben, Anm. 1), S. 103. 
Nach dem Tod seiner Tante, der Regentin Margarethe von Österreich Ende 1530, begann Karl V. nach fast einem Jahr damit, die Verwaltung und das polizeiliche System in seinen niederländischen Gebieten zu reformieren (Das mcinte, sie weiter zu zentralisieren). Auf diese Weise wollte er seiner Schwester Maria von Ungarn, die 1531 de facto die Aufgaben einer Regentin übernahm, mit einem so gut wie möglich funktionierenden Staatsapparat ausrüsten. In dicsem Kontext verlangte Kaiser Karl, dass die Ketzerei in den Niederlanden so streng wie möglich bestraft werden sollte, sicherlich nachdem in Deutschland die behutsamere Vorgehensweise fehlgeschlagen hatte und dic Lutheraner dort eine Gruppe mit eigener konfessioneller Identität auszumachen begannen. Während der Sitzung der Generalstaaten der "Païs de pardecha" oder "I anden van herwaerts overe", 90 im Oktober 1531 in Brüssel, bat Kaiser Karl den Rat ausdrücklich um dic Zustimmung der Staaten betreffs der Verfolgung der Ketzer. ${ }^{91}$ Am 7. Oktober 1531 ließ er während der Sitzung der Gencralstaaten und unter seiner Anwesenheit das Ketzerplakat von 1529 noch einmal feierlich vorlesen. Karl V. ordnete an, dass dicses Plakat am 15. November noch einmal in allen Staaten "de pardecha" verkündet werden musstc. Mchr noch, von da an mussten alle sechs Monate die Befehle neu verkündet werden, damit sich niemand auf Unwissenheit berufen konnte. Die Maßnahmen des Plakates von 1529 wurden während der feierlichen Sitzung vom 7. Oktober 1531 bekräftigt. ${ }^{92}$ Bei einem genaueren Blick auf den Inhalt dieses Plakates ${ }^{9.3}$ fällt als erstes auf, dass keine Klausel mehr eingebaut war, die den Menschen die Möglichkeit gegeben hätte, 'ketzerische' Schriften bei den Gerichten abzugeben. Auf den Besitz solcher Schriften stand sofort dic Todesstrafe. Wcitcrhin fällt auf, dass die Strafen für diejenigen erschwert

${ }^{90}$ Damit waren die Besitzungen des Kaisers in den Niederlanden gemcint.

${ }^{91}$ John Gilissen, 'Les Elats Généraux des Pays de par deça (1464-1632)', in Assemblées d'Etats. 500 ans de vie parlementaire en Beligique 1464-1964 (Löwen, 1965), 261-321, S. 303-304 und 309-310.

${ }_{92}$ Lamecre, Hg., Recueil des ordonnances, Band 3 (siehe oben, Anm. 1), S. 265-273.

${ }_{93}$ Ibid., S. 262-265. Ubrigens findet man im Plakat keine Spur mehr von den Privilegien, dic Flandern Ende 1529 noch hat retten können, so die Non-Konfiszierung der Güter Verurteilter und die Bestrafung derer, die Unschuldige der Ketzerei bezichtigt haben. "Les conseils provinciaux ne firent aucune difficulté quant à la publication, mais bien les villes de Gand, de Bruges et d'Ypres, ainsi que le Franc de Bruges, à l'encontre du refus de respecter leur privilège de non-confiscation des biens" (Goosens, Les inquisitions, Band 1 (siehe oben, Anm. 1), S. 56; vgl. Fühner, Die Niederlande (siche oben, Anm. 1), S. 186-187). 
werden, die ein Buch ohne vorherige Genchmigung durch die Obrigkeit herausgaben. Statt der Geldbuße von 500 goldenen carolus wurden sie zum Schafott verurteilt. Hinzu kam eine unauslöschbare körperliche Folter: mit einem Brandeisen musste ihnen ein Kreuz ins Gesicht (meistens auf dic Wange) cingcbrannt und ein Auge ausgestochen oder eine Hand abgehackt werden. Der Richter hatte dies je nach Schwere der Zuwiderhandlung auszuwählen. So wurde dic mittclalterliche Strafe für Unzuverlässigkeit oder Falschheit im Umang mit der Obrigkeit auf dic Ausgabe cincs Buches ohne deren Genehmigung angewandt. Obwohl im Plakat nicht ausdrücklich angeführt, galt dicse schwere Strafe offensichtlich auch für diejenigen, dic eine Übersetzung des Neuen Testamentes in dic Volkssprache publizierten oder aus dem Ausland einführten, ohne dass der Staat dies genehmigt hatte. ${ }^{94}$ Was Holland betrifft, muss darauf hingewiesen werden, dass vielleicht am 7. Oktober 1531 zum ersten Mal das betroffene Plakat verkündet wurde. Für eine frühere Veröffentlichung 1529 lassen sich keine Anhaltspunkte finden. ${ }^{95}$ So erhielt Holland erst 1531 Kenntnis von der Forderung des Kaisers, dic Todesstrafe und die anderen schweren Strafen ungemildert anzuwenden, ohne auf die konkreten (eventuell mildernden) Umstände des Einzelfalles einzugehen. Wie der Rat von Flandern zwei Jahre zuvor fand auch Holland, dass bestimmte Strafen unmäßig waren, so die Todesstrafe auf bloßen Besitz verbotener Bücher. ${ }^{96}$ Mechelen sollte in den folgenden Jahren mchrmals deutlich machen, dass es in Holland mit dem Lavieren bezüglich des crimen laesae majestatis divinae vorbei sein sollte. Eine dermaßen kompromisslose Haltung machte es dem Rat von Holland unter Leitung von Gerrit van Assendelft, der versuchte örtliche juristische und religiösc Sensibilitäten soweit wic möglich zu respektieren,

9. Das Plakat von 1529 legte dic Bußc für dic Publikation oder die Einfuhr von Bibeln in der Volkssprache ohne Erlaubnis des Staates ausdrücklich mit 500 goldenen carolus fest. Auch die Buße für die illegale Herausgabe anderer Werke wurde ausdrücklich angeführt: ebenfalls 500 goldene carolus. Das Plakat von 1531 gab die Buße für dic illegale Herausgabe von Bibeln in der Volkssprache nicht mehr explizit an. Im folgenden Abschnitt wurde als Strafe für die Veröffentlichung von Büchern ohne vorherige Approbation durch den Staat eine körperliche Verstümmelung angedroht. Aus dem Parallelismus können wir ableiten, dass letztere Strafe von Anfang an auch für die illegale Veröffentlichung von Bibeln in der Volkssprache galt.

${ }^{95}$ Vgl. u.a.: 'Tracy, 'Heresy Law and Centralization' (siche oben, Anm. 51), S. 289, Anm. 16.

${ }^{26}$ Duke, Reformation and Revoll (siche oben, Anm. 6), S. 158; Jacob Gijsbert de Hoop Scheffer, Geschiedenis der kerkhervorming in Nederland van haar ontstaan tot 1531 (Amsterdam, 1873), S. 475, Anm. 3. 
nicht leicht. Das Plakat von 1531 bedeutete dann auch das Ende einer Periode, da es das letzte Plakat darstellt, das sich ausdrücklich in dic Tradition des Wormeser Ediktes einordnete. Der Norden hatte zudem seit dem Beginn der dreißiger Jahre mit einer breiten Unterstützung für die Anabaptisten zu rechnen, womit die Reformation dann auch inhaltlich in eine neue Phase eintrat. ${ }^{97}$ Aus dem Gebiet von Flandern und Holland sind uns aus den frühen dreißiger Jahren verschiedene Prozesse bekannt, aus dencn deutlich zu werden scheint, dass die Lektüre und Besprechung der Bibel in Konventikchn schnell zu 'ketzerischen' Auffassungen zu führen schien und entsprechend bestraft wurdc. ${ }^{98}$ Andererseits wurden, wie wir noch sehen werden,

97 'I'racy, 'Heresy Law and Centralization' (siehe oben, Anm. 51), S. 290-304.

${ }_{98}$ Auch aus Veere gibt es Berichte über geheime Konventikel für die Jahre 1529. 1530, an denen vor allem Handwerker teilnahmen. Finer aus der Gruppe befand sich jewcils vor dem Versammlungsraum, um zu verhindern, dass Informanten lauschen würden. Dort ging es um typisch evangelische Themen wie die Abendmahlslehre, den freien Willen und Fegefeuer. In einigen Fällen wurde ein Text aus der Heiligen Schrift explizit als Ausgangspunkt genommen. 1529 und 1531 gab es eine Untersuchung dieser Konventikel, aber zu ernsthaften Verfolgungen scheint es nicht gekommen zu sein (de Hoop Scheffer, Geschiedenis der kerkhervorming (siehe oben, Anm. 96), S. 512-516). Auch in der Gegend der Stadt Leiden hielt man mindestens seit Ostern 1530 Zusammenkünfte, bei denen dic Bibel gelesen und auf 'cvangelische' Weise ausgelegt wurde. Hicr gab es ebenfalls cine gerichtliche Untersuchung (Laurentius Knappert, De opkomst van het protestantisme in eene Noord-Nederlandsche stad. Geschiedenis van de Heronming binnen Leiden van den aanvang tot op het beleg (Leiden, 1908), S. 119). J. Decavele hat für die alte Grafschaft Flandern angedeutet, dass Bibellesergruppen besonders aktiv waren im Industriegebiet an der Schelde zwischen Gent und Oudenaarde und in letztere Stadt sclbst. In Oudenaarde waren mindestens seit 1526 verdächtige Schriften im Umlauf. "Der Magistrat befasste sich anfangs wenig damit, kam aber 1532 doch zu der Entdeckung, dass auch auf seinem Rechtsgebiet einer kleiner Kern entstanden war, der mehrere verbotene Bücher besal3. Einer aus dieser Gruppe, Arent de Man, dessen Beiname 'das Licht Gottes' vicllcicht auf seine Rolle bei den Bibellesern schließen lässt, wurde im folgenden Jahr enthauptet. Jeroen de Muclencere legte man auf ewig Schwcigen auf, indem man ihm die Zunge durchstach. Auch der Lehrer und Rhetoriker Pieter Scuddematte gehörte zu dieser ersten Gruppe von Bibellesern" (Decavele, De dageraad (siehe oben, Anm. 4), S. 268; unsere Übersetzung). Uber letzteren schreibt Decavele an anderer Stelle, dass er nach einer Verurteilung 1532 und der folgenden Verbannung aus Oudenaarde ein anderers Wirkungsgcbiet suchtc. Wic viele anderc zog cr nach Antwerpen, wo er sich als Lehrer niederließ und von neuem in Rhetorikervereinen aktiv wurde. 1545 wurden die Rhetoriker wegen einer Reihe seiner Schriften verhaftet. In der Literatur wird behauptet, dass er an einer niederländischen Bibelübersetzung mitgwirkt habe, was genauso bezweifelt werden kann. 1547 wurde er in Antwerpen enthauptet. J. Decavele hat außerdem darauf hingewiesen, das Beispiel Jan Taelmans mache dcutlich, dass vor 1533 in den Dörfern zwischen Gent und Oudenaarde Bibeln in der Volkssprache verbreitet waren. Einige Gläubige brachten sogar cin flämisches Neues Testament 
sehr schnell offizielle Genehmigungen ("cum gratia et privilegio") vergeben an Bibelübersetzungen, dic man als annehmbar betrachtete.

\section{Eine Grauzone tolerierter Ausgaben?}

Es ist deutlich, dass dic Kctzerplakate sich vor allem gegen die Bibelausgaben wandten, die cine nicht-rechtgläubige Übersetzung und zusätzlich reformatorische Einleitungen, Zusammenfassungen und/oder Glossen enthiclten. Dergleichen Ausgaben lenkten den gewöhnlichen

mit zur Kirche. Decavele führt den Fall eines Gläubigen aus Dikkelvenne an, der "hoorde preken 't evangelye vanden daghe, dede open zynen bouckc endc zcydc totten ghonen daer neffens hem zaten: 'ziet dacr stacdt ghescreven ende 't es zo'" (Decavele, De dageraad (siehe oben, Anm. 4), S. 268. Im gleichen Dorf Dikkelvenne, aber auch in umliegenden Dörfern, wurden am Sonntag nach dem Hochamt in den Gasthäusern sogleich dic Abschnitten aus den Evangelien kommentiert, die die I.eute gerade in der Messe gehört hatten, wobei man vor allem die Rechtmäßigkeit der Bibelübersetzungen besprach. Wer sich sehr interessierte, schloss sich nach und nach einer festen Bibelgruppe an, die vom einem Landwirt aus Dikkelvenne, Jan Taelman, und den Pastören von Hermelgem und Sinte-Maria-Latem, Jan de Wulf und Michiel Hannins, geleitet wurde. Während einer Zusammenkunft in bestimmten Herbergen las jemand einen Abschnitt aus dem Neuen Testament und gab dazu eine kurze Erläuterung. Dann zogen sich die Teilnehmer zu zweit zurück, um den gehörten Text zu besprechen. Zum Abschluss wurden in der Versammlung aller die verschiedenen Findrüke ausgetauscht. Keiner der an solchen Bibelgruppen teilnehmenden Priester oder Laien dachte hier daran, cine von der Kirche abweichende Lehre zu begründen. Im Gegenteil, jeder nahm voll und ganz am kirchlichen Leben teil. So weiß man, dass die Bibelleser als Gruppe in dem einen oder anderen Dorf sogar an den Prozessionen teilnahmen. Gerade dergleichen gemeinsames Auftreten und ihre geschlossene wenn auch nicht geheime - Versammlung bewirkte, dass dic Bibclgruppen von gewissen Verdächtigungen umgegeben waren. Vor allem nachdem der Pastor von Dikkelvenne, selber nicht Mitglied einer Bibelgruppe, offentlich cine Verurteilung der 'Neuerer' ausgesprochen und dabei an die Strenge der Plakate gegen Ketzerei erinnert hatte, ergab sich eine Polarisicrung. Vicle Bewohner der Gegend betrachteten die Bibelleser als Lutheraner, ohne genau zu wissen, was das meinte. Andererseits fiel in der Bibelgruppe vicl Kritik an bestimmten Geistlichen des Gebietes und besonders am gerade genannten Pastor von Dikkclvenne. Ende 1534 hatte der Rat von Flandern von den umstrittenen Versammlungen Wind bekommen. Am 28. November wurde Pastor Michiel Hannins von Sinte-MariaLatem zum Verhör mitgenommen, aber vermutlich kurze Zeit später wieder frei gelassen. Im Juni 1535 begann cine gerichtliche Untersuchung, die in den folgenden Monaten zur Anhörung sechs Verdächtiger führte. Jan 'Taelman und die anderen wurden am 20. November 1535 öfentlich gegeißelt und erhielten Geldbußen von 30 bis 150 Gulden. Nach einem Urteil des Rates von Flandern polarisierten sich dic Meinungen und Gemüter bezüglich des Pastors von Sinte-Maria-Latem, Michicl Hannins, immer mehr, der immer deutlicher ketzerische Standpunkte verkündigte (Für eine genauere Schilderung: Ibid., pp. 268-271). 
Leser unverkennbar in eine 'ketzerische' Richtung. Zum harten Kern gehörten vor allem die Lutherausgabe des Amsterdamer Verlegers Doen Pietersoen von 1523, ${ }^{99}$ das Deventer Neue Testament Albert Pafracts von 1525 (mit Neuauflagen) und die Antwerpener Ausgaben von 1525, die durch die Löwener Zensoren ausdrücklich im Ketzerplakat von 1529 genannt waren.

Um diesen harten Kern ausgesprochen reformatorischer Bibeln sammelte sich einc Grauzone von Lutherübersetzungen ohne 'gefährliche' paratextuelle Elemente. Dabei müssen wir uns stets vor Augen halten, dass eine durch einen 'Ketzer' angefertigte Bibelübersetzung nicht automatisch als schlechte Übersetzung abgewiesen werden musste. Außerdem gab es Ausgaben mit humanistisch-erasmianischem Charakter, neben 'rechtgläubigen' Übersetzungen, die auf der Vulgata basierten. Und es kamen allerlei Mischformen vor. Diese Vielfalt an Texten spiegelt das breite Spektrum religiöscr Überzeugungen wieder, die in den Niederlanden lebendig waren. Von ciner deutlichen konfessionellen Abgrenzung war noch nicht die Sprache. So gab es viele, die der katholischen Kirche treu blieben, Intellektuelle, die mit der humanistischen Bewegung sympathisierten, neben Leuten, die (teilweise) reformatorischen Gedankengut anhingen, bis hin zu überzeugten Lutheranern und andere Dissidenten. Die Grenzen zwischen diesen Richtungen waren nicht immer deutlich zu bestimmen. ${ }^{100}$ Herausgeber wirkten auf die konfessionel in der Schwcbe sich befindenden Bibelleser mit immer neuen Textausgaben ein, in der Hoffnung im Konkurrenzkampf eine gute Position erringen zu können. ${ }^{101}$ Ohne vollständig sein zu können, so wollen wir doch auf die bekanntesten Ausgaben hinweisen.

Adriaen van Berghen hatte 1523 als erster in den Niederlanden eine Übersetzung herausgebracht, die, mit Ausnahme der Briefe, ganz auf Luthers Septembertestament beruhte, aber nicht dessen Vorreden und Glossen aufgenommen hatte. Er hatte selbständig dem Luthertext "corte bedudenisse" oder knappe Inhaltsangaben vor den Kapitel hinzugefügt, eine Praxis, die er der Übersetzung Johan Pelts entliehen hatte. Diese Inhaltsangaben standen zudem auf der ersten Seite

49 Wir erinnern daran, dass auch die Bibelübersetzung Johan Pelts, herausgegeben von Doen Pictersoen 1522, ausdrücklich zu den verbotenen Fassungen gerechnet wurde.

${ }^{100}$ Vgl. De Bruin, De Siatenbijbel (siehe oben, Anm. 2), S. 66.

101 Darauf wird hingewiesen von De Bruin, ibid., S. 125. 
angckündigt. So handelte es sich hicr um eine Ausgabe, die der Gefahrenzone sehr nahe kam. ${ }^{102}$

Cornclis Henricsz. Lettersnijder gab 1524 in Delft eine Ubersetzung von Erasmus' Novum Testamentum heraus. Im Vorspann finden wir zunächst "Een corte vermaninghe", einen Ansporn für jeden, die Heilige Schrift zu lesen, dic eine Übersctzung der Praefatio von Erasmus' Novum Testamentum ist. In einer zweiten Vorrede "Allen Christen menschen broederen" wird deutlich gemacht, wie die Herausgeber des Textes vorgegangen waren, wobei Erasmus viel Lob erntete (Beide Vorreden bereits im Neuem Testament van Berghen's 1524). Aufgenommen wurde auch ein Brief von Papst Leo X., der die Lektüre von Frasmus' Neucm Testament cmpfahl und damit der Übersetzung den Charakter kirchlicher Autorisicrung verlieh. Dem folgte zusätzlich cine kirchliche Lescordnung, die auf der Titelseite angekündigt war und den gut kirchlichen Charakter dieser Ausgabe noch betonte. Wie bercits gesagt, bot der Text selbst cinc Übersetzung von Erasmus' Novum Testamentum (vicllcicht der zwciten Auflage von 1519). ${ }^{103}$ In diesem Text hatte man die Stellen markicrt, die Erasmus gegenüber der Vulgata zusätzlich hatte und umgekchrt. Wo sich der Text von Erasmus und die Vulgata unterschieden, warcn dic aus dieser offiziellen kirchlichen Bibelversion stammenden Varianten, natürlich in Übersetzung, am Rand wiedergegeben. Dies war der Beginn eines wissenschaftlichen Umgangs, der für das sechzehnte Jahrhundert allerdings die Ausnahme bildcte. S.W. Bijl deutet andererseits an, dass in der Einleitung zum Römerbrief Sympathien für lutherische Idcen durchscheinen: Der sündige Mensch wird nicht durch eigene Verdienste, sondern allein durch den Glauben an den seligmachenden Christus gerechtfertigt. Der(Dic) Übersetzer musste(n) dann wohl auch in den Kreisen der ersten Luthersympathisanten Delfts gesucht werden. Lettersnijders Ausgabe wurde nicht von der Zensur getroffen, weder 1529 noch später. ${ }^{104} 1525$ besorgte der

${ }_{102}$ De Bruin, De Statenbijbel (siehe oben, Anm. 2), S. 76-79; Den Hollander, De Nederlandse bijbelvertalingen (siche oben, Anm. 2), S. 46-47; 213-214; 264-267.

${ }^{103}$ Bijl, Erasmus in het Nederlands (siehe oben, Anm. 2), S. 33. C.C. de: Bruin geht davon aus, dass es um die dritte Auflage von 1522 geht (De Bruin, De Statenbijbel (siehe oben, Anm. 2), S. 105).

${ }_{101}$ De Bruin, De Statenbïbel (siche oben, Anm. 2), S. 105-109; Bijl, Erasmus in het Nederlands (siehe oben, Anm. 2), S. 32-50; Den Hollander, De Nederlanse bïbelverlatingen (siche oben, Anm. 2), S. 56-58; 218; 289-291; Den Hollander, 'De edities van het Nieuwe 'Testament door de Delftse drukker Cornelis Henricsz. Lettersnijder', Nederlands Archief voor Kerkgeschiedenis 75 (1995), 165-187. Für Gründe, warum 
Antwerpener Drucker Jan (1) van Ghelen eine wortgetreuc Neuausgabe von Lettersnijders Werk. Natürlich wurde auch diese Edition nicht von der Zensur belangt. ${ }^{105}$

Der Kölner Drucker Hiero Fuchs (Hcro Alopecius) brachte im gleichen Jahr 1525 einc niederländische Übersetzung des Luthertextes (in der Version Adriaen van Berghens) auf den Markt. Diese war crgänz1 um einige Randbemerkungen, die vor allem der Vulgata entnommen waren und zum Tcil auf Erasmus zurückgingen. Der Ausgabe gingen zwei Vorworte voraus, die Laicn zur Schriftlesung anspornten und die stark vom Prolog der französischen Ausgabe des Neucn Testamentes von Iefêvre d'Étaples (1523) beeinflusst waren. Bei Hicro Fuchs taucht allerdings ein neues Phänomen auf: Auf die Titelseite setzte er den Text Markus 16, 15-16, der die Bedeutung der Bibellektürc unterstreichen sollte. ${ }^{106} \mathrm{Er}$ sclbst und nach scinem Beispiel viele andere Drucker hofften, dass dieses oder ein anderes Zitat dic Menschen, die den neuen Ideen anhingen, dazu bewegen würde, dic Ausgabe zu kaufen. ${ }^{107}$ Nach und nach würden die Zensoren auch an der Veröffentlichung derartiger Schriftzitate auf der Titelseite Anstoß nehmen. Dic rcich bebilderte Ausgabe von Hicro Fuchs ist darum auffallig, weil sie neben der von Hans (1) van Ruremund dic cinzige niederländische $\Lambda$ usgabe war, die cs gewagt hatte, bei den Illustrationen der Apokalypse die päpstliche Tiara im elfien Bild auf dem Kopf des 'lieres aus dem Abgrund und auch im sechzehnten Bild auf dem Kopf des Tieres zu belassen, sowie auf dem Kopf der Hure Babylon in der siebzehnten Auflage. Es waren ja die Blöcke der Fuchs'schen Apokalypsc-Illustrationen, dic im Verlauf des Jahres 1525 durch Hans (1) van Ruremund für sein Antwerpener Neues Testament benutzt wurden. ${ }^{108}$ Diese in Köln gedrucktc Ausgabe war

Lettersnijders Ausgabe nicht auf den Index gesctzt wurde, vgl. dic These desselben Verfassers: Den Hollander, Verboden bïbels (siche oben, $\Lambda \mathrm{nm}$. 3), S. 18-19.

${ }^{105}$ De Bruin, De Statenbïbel (siehe oben, Anm. 2), S. 108; Bijl, lirasmus in het Nederlands (siehe oben, Anm. 2), S. 45; Den Hollander, De Nederlandse bïbelvertalingen (siehe oben, Anm. 2), S. 50; 219-220; 298-300.

1016 "Gaet in alle die werelt/ cnde predict dat Evangelium alle creaturen/wie dat gheloofft/cnde ghedoopt is/ sal salich sijn".

${ }_{107}$ De Bruin, De Statenbijbel (siehe oben, Anm. 2), S. 81-84; Den Hollander, De Nederlandse bïbelvertalingen (siehe oben, Anm. 2), S. 60-61; 219; 295-297.

${ }_{108}$ Rosier, De Nederlandse bijbelillustraties (siche oben, Anm. 71), S. 5-6; 48-49; 128130. Neben den Ausgaben von Hans (1) van Ruremund und Hiero Fuchs finden wir auch in den Bibclausgaben von Henrick Peetersen van Middelburch von 1535 und 1538 cine Abbildung der Hure Babylon mit einer päpstlichen Tiara auf dem Kopf. 
vielleicht in Löwen nicht bekannt, es sei denn, dass dic magistri Lovanienses meinten mit der unbestimmten Andeutung "Johannes 7.cl" eben diese Kölner Ausgabe.

Ende 1525 erstellte der Antwerpener Drucker Merten de Keyser eine Ausgabe für den Verlag Govaert van der Haeghen. Faktisch war die Übersetzung eine Mischung des Luthertextes (Adriacn van Berghen, 1524) mit Erasmus'schen Elementen (Lettersnijder, 1524). Hier und da hat man den Text gemäß Erasmus' Nozum Testamentum von 1519 selbständig korrigicrt. Diesc Ausgabe nahm auch dic Vorrede des Erasmus auf, die alle Menschen zum Lesen der Schrift aufforderte und die gleiche war wie die in der Ausgabe von van Berghen (1524), Lettersnijder (1524) u.a. In der Ausgabe, die Merten De Keyser für Govacrt van der Haeghen besorgte, stand auf der Titelseite auch das Zitat aus Mk 16, 15-16, das wir bereits bei Fuchs antrafen. ${ }^{109}$ Obwohl diese Ausgabe für de Bruin reformatorisch inspiriert war, ${ }^{110}$ hat sie nicht den Argwohn der Behörden geweckt und wurde deshalb in der 'Löwener Zensur' des Ketzerplakates von 1529 auch nicht ausdrücklich genannt.

Daneben gab es die Ausgaben des Antwerpener Druckers Michiel Hillen van Hoochstraten, der 1527 die Delfter Erasmusübersetzung als Grundlage nahm, aber sie vereinfachte, um sie zu 'vulgatisieren': Vulgatavarianten, die vorher am Rand standen, setzte Michiel Hillen an die Stelle des Erasmustextes. Und er entfernte die Abschnitte aus der Übersetzung, die Erasmus über den Vulgata-Text hinaus besaß. An einigen Stellen korrigierte er selbständig den niederländischon Erasmustext gemäß der Vulgata. Michicl Hillen drucktc zusätzlich die Epistel aus dem Alten Testament, dic in der Iiturgie vorkamen, ab. Dic Vorreden der Lettersnijder-Ausgabe von 1524 ließ er selbstverständlich weg. So erreichte es dieser Antwerpener Drucker, eine Übersetzung zu bieten, die für den Staat akzeptabel und außerdem

${ }^{109}$ De Bruin, De Statenbijbel (siehe oben, Anm. 2), S. 109-111; Bijl, Erasmus in het Nederlands (siehe oben, Anm. 2), S. 45-48; Den Hollander, De Nederlandse bijbelvertalingen (siehe oben, Anm. 2), S. 62-63; 220-221; 301-303.

110 ". . . das zeigt eine Übersetzung von Matthäus 4, 17 mit 'Hebt berou'. Dic: kurzen Inhaltsangaben zu den Kapiteln umfassten gewagte $\Lambda$ ussagen wie: 'Na dic liefde en is geen groter gave, dan dye gave der prophetien, dat is die wtlegginge der heyligher scrift, welcke ons allen gheoorloft is, wtghescheeden, dat dic vrouwen ...' (zu l Korinther 14) und 'Onder dic Christen en is gheen overheyt, want cen yegelijck wil des anderen dienaer zijn wt liefden' (zu Römer 13). Erstere erkläre das Studium der Schrift durch Laien für crlaubt, die zweite verwerfe die Autorität einer Obrigkeit" (De Bruin, De Statenbigbel (siehe oben, Anm. 2), S. 110; unsere Übersetzung). 
für den liturgisch-kirchlichen Gebrauch geeignet war. ${ }^{11}$ Michiel Hillen van Hoochstraten würde wegen dicser und seiner späteren Ausgaben mit der Zensur keine Probleme bekommen.

Auch unter katholischen Gläubigen in den entwickelten und rclativ gut alphabetisierten Niederlanden tauchte die gleiche Frage auf, nämlich die nach einer autorisierten Bibelübersetzung. Die verschiedenen Behörden in den Niederlanden erkannten diese Anfrage --- eher in der Praxis als in der Theorie - als gerechtfertigtes Verlangen an. Sic begriffen, dass eine simple Verweigerung viele Gläubige in die Arme des Luthertums trciben würdc. Außerdem gehörten die Stadtmagistrate und Juristen in den Provinzräten selbst der gebildeten, humanistisch gesinnten Oberschicht an. ${ }^{12}$ Darum legten in den Niederlanden die lokalen Behörden die kaiserlichen Plakate über die Bibclausgaben cher großzügig aus. Auch ist klar, dass die Zensur in den ersten Jahren vor allem Ausgaben strengen oder explizit reformatorischen Charakters, der in Glossen, Summarien und/oder Vorreden zum Ausdruck kam, im Auge hatte. Andere Ausgaben wurden in Ruhe gelassen.

Auch und vor allem der Stadt Antwerpen war eine dehnbare Bibelpolitik wichtig. ${ }^{113}$ Antwerpen war cine kosmopolitische Hafenstadt, in der Menschen aus verschiedenen Ländern und mit unterschiedlichen religiösen Überzeugungen lebten. Antwerpen war viel daran gelegen, diese Stellung einer offenen Hafenstadt zu bewahren. Der Magistrat der Stadt wollte dann auch den vielen ausländischen Geschäftsleuten vor Ort keine Schwierigkeiten machen. Diese ausländischen Niederlassungen waren übrigens auf verschiedenen Ebenen der örtlichen Rechtssprechung entzogen. Natürlich gab es in der Handelsstadt Antwcrpen auch viele Bankiers und Finanziers. Das internationale Handelsnetz und die Präsenz von Investoren mit anschnlichem

11 De Bruin, De Statenbijbel (siehe oben, Anm. 2), S. 108; Bijl, Erasmus in het Nederlands (siehe oben, Anm. 2), S. 48-49; Den Hollander, De Nederlandse bïbelvertalingen (siehe oben, Anm. 2), S. 81; 225-226; 336-338; Den Hollander, 'Het Nicuwe Testament. Cornelis Henricsz. Lettersnijder' (siehe oben, Anm. 104), S. 183.

${ }^{112}$ Duke, Reformation and Revolt (siehe oben, Anm. 6), S. 153-159.

113 Leon Voet, 'De typografische bedrijvigheid te Antwerpen in de $16 \mathrm{c}$ ceuw', in Antwerpen in de XVIde ceuw. Genootschap voor Antwerpse geschiedenis (Antwerpcn, 1975), S. 233-255; Andrew G. Johnston und Jean-François Gilmont, 'L'imprimerie et la Réforme à Anvers', in La Réforme et le liure, Hg. Gilmont (siehe oben, Anm. 33), S. 191-216. Vgl. auch: De Bruin, De Statenbijbel (siche oben, Anm. 2), S. 121-124; Johnston, 'L'imprimerie et la Réforme aux Pays-Bas' (siehe oben, Anm. 33), passim; Marnef, Antwerpen (siehe oben, Anm. 34), S. 65-68. 
Kapital ließ Antwerpen während seines Goldenen Jahrhunderts auch zum wichtigsten Vcrlagszentrum der Niederlande werden: In der Zeit von 1500 bis 1540 leisteten die Druckereien ungefähr $55 \%$ der gesamten Buchproduktion der Niederlande. Auf europäischer Ebene lag Antwerpen an dritter Stelle, hinter Venedig und Paris, und bcherrschte dadurch das Druckereiwesen im gesamten NordwestEuropa. Mit anderen Worten, für den Erhalt des Wohlstandes der Stadt war es wesentlich, dass viele auswärtige Kaufleute in der Stadt mit cinem Klima religiöser Toleranz rechnen konnten und die Druckereien eine größtmögliche Freiheit genossen. Selbst für den Kaiser hatte natürlich das Wohlergehen Antwerpens Bedeutung. Zur Finanzierung seiner zahlreichen europäischen Kriege war Karl V. vor allem auf die Steueraufkommen der ökonomisch wohlhabenden Kernprovinzen der Niederlande angewiesen, namentlich auf Holland, Flandern und besonders Brabant. Der Antwerpener Kapitalmarkt stellte den größten Geldgeber dar. Die Krone hatte darum überhaupt kein Interesse daran, die Handelsprivilegien und die behördliche Autonomie Antwerpens zu sehr zu beschränken. ${ }^{14}$ Das war der Grund für einen "notgedrungenen Pragmatismus", obwohl Karl V. in Theorie "ein Befürworter weitgehender Zentralisation und religiöser Uniformität" war. ${ }^{155}$ Die Verbreitung niederländischer und französischer Bibelausgaben ${ }^{116}$ bildete für die Antwerpener Drucker dann auch kaum ein Problem, obwohl erstere oftmals auf Luthers Bibclübersetzung zurückgingen. ${ }^{17}$

114 Willem Pieter Blockmans, 'De vorming van een politieke unie (14de-16de ccuw)', in Geschiedenis van de Nederlanden, Hg. J.C.H. Blom und Emiel Lamberts (Amsterdam, 1994), S. 133-135.

${ }^{115}$ Marnef, Antwerpen (siehe oben, Anm. 34), S. 44 (unsere Übersetzung).

116 Der Franzose Martin Lempereur oder Merten De Keyser licß sich 1525 auf Anraten Jacques Lefevre d'Étaples' in Antwerpen nieder. Nach der Verurteilung von Bibelubbersetzungen in der Volkssprache durch Pariser Theologen war der Humanist zurceht der Meinung, dass er in Antwerpen größcre Freihcit haben würde, seine französische Ubersetzung der Hl. Schrift zu publizieren. Die Auflagen waren zur Ausfuhr nach Frankreich aber auch für die französischsprachigen Gebiete der Nicderlande bestimmt.

117 Der Buchbestand der Antwerpener Drucker umfasste ein sehr breites Spektrum (Voet, 'De typografische bedrijvigheid' (siehe oben, Anm. 113), S. 241-243). Der größte Teil der Buchproduktion betraf aber religiöse Literatur. Neben gut katholischen Werken wurden ab den zwanziger Jahren auch viele Schriften mit lutherischevangelischem Einschlag gedruckt und das sowohl auf Iatein wic in der Volkssprache. Die Präsenz deutscher Kaufleute in der Stadt sorgte für eine regelmäßige Zufuhr neuer Bücher Luthers. Wic angedcutct, markicrten dicse Schriften selten strikt konfessionelle Grenzen oder nahmen keine scharfe Polemiken mit den Gegnern auf. 
Auch theologisch gesehen war dic Suche, was als Übersetzung akzeptabel und was unakzeptabel war, in den ersten Jahren voll im Gange. Noch stand kein festes Kriterium dafür zur Verfügung, was im nicderländischen Sprachgebiet als autorisierte katholische Übersetzung gelten konnte und was nicht. Fine Übersctzung in Übereinstimmung mit der Vulgata, in der sich die Lehre der Kirche getreu wiederfand, blicb alles in allem die Maßgabe. Diskussion und eine eventuelle Korrektur von Übersetzungen waren stets möglich. ${ }^{118}$ Wie bereits angedeutet: Eine durch einen 'Ketzer' erstellte Bibelübersetzung musste an sich noch keine schlechte Übersetzung sein. Anstoß nahm man vor allem an reformatorischen Glossen und Einleitungen, weniger an der Übersetzung als solcher. ${ }^{119}$ Der (notgedrungene) Pragmatismus

Meist handelte es sich um cvangelische Erbauungsliteratur oder Kommentare der Hl. Schrift, die Festigung der Gläubigen anstrebten. Englische frühreformatorische Literatur, die in Antwerpen gedruckt und von da (hcimlich) ausgcführt wurde, war von ganz anderer Art: Sie wurzelte in den radikalsten Elementen der frühen reformatorischen Bewegung in England und wies einen sehr polemischen Charakter auf. Aus diesen Gründen nahmen vicke Antwerpener Drucker Zuflucht zu einem Pseudonym. Das Los von Christollel und Hans (1) van Ruremund licß dic Drucker bei Drucken der englischen Tyndale- und Coverdale-Bibeln vorsichtig scin (Johnston und Gilmont, 'L'imprimerie et la Réforme à Anvers' (siehe oben, Anm. 113), S. 209-210; 215-216).

11 Ein klassisches Beispicl für theologische Implikationen unterschiedlicher Nuancen in der Übersetzung bielet der bereits genannte Text Matthäus 4, 17. In diesem Vers ruft.Jesus, wie Johannes der Täufer, zur "metanoia" auf. In der Vulgata stand: "poenitentiam agite", womit die kirchliche Bußpraxis begründet werden konnte. In Erasmus' Norum Instrumentum von 1516 stand: "poeniteat vos", in seinem Norum Testamentum von 1519 jedoch: "resipiscite", das mehr die innerliche, moralische Bekehrung betonte. Luther übersetzte: "Bessert euch" (nach 1526: "Thut busse"). Adriaen van Berghen druckte in der crsten Lutherübersetzung von 1523: "Betert u". Cornelis Lettersnijder schrieb 1524 auch: "Betert u" und nahm am Rand die Vulgatavariante: "Doet penitencie" auf. Die Ausgabe, die Merten de Keyser 1525 für Govaert van der Haeghen druckte, enthielt die Ubersetzung: "Hebt berou". Die Ausgaben von Jan (1) van Ghelen von 1526 und 1528, die sich auf die von M. de Kcyser für G. van der Hacghen zurückführen, schrieben am Rand: "Daer hier staet hebt berou daer hebben dandre betert u of doet penitencie wele al op een uut comt". Michiel Hillen van Hoochstraten, der sich 1527 auf dic Ausgabe von Lettersnijder stützte, verlegte die Vulgatavariante vom Rand in den Text selbst. So hieß es "Doet penitencie". Die Vorstermanbibel von 1528, die ein offizielles "cum gratia et privilegio" erhalten hatte, schrieb dennoch: "Hebt berou".

119 In diesem Sinn beantwortet ein Großteil der 'modernen' niederländischen Bibeln aus dem ersten Jahrzehnt den bereits geschätzten allgcmeinen Charakter der evangelischen Literatur in den Niederlanden: sehr selten findet man einen polemischen T'on darin oder die starke Betonung konfessioneller Grenzen. Vielmehr hatten sie einen devotionalen oder erbaulichen Zug (mit gleichwohl einem kräftigen lutherischen Einschlag). Zurecht stellen A.G. Johnston und J.-F. Gilmont fest: "Par aillcurs, il n'est pas toujours aisé de déterminer la tendance confessionelle d'une 
der Antwerpener Stadtbehörde fand so cin Pendant in der Flexibilität der Löwener Theologen/Inquisitoren. Mit dieser "Toleranz" verbindet sich der Name Nicolas Coppin. ${ }^{120}$

traduction, surtout durant ces premières années de la Réforme... À l'époque, le caractère 'hćrćtique' d'une traduction se situe moins dans la version elle-même que dans tout ce qui accompagne le texte sacré: préfaces et introductions, résumés en tête des chapitres, notes marginales, tables en fin de volume. Il n'est d'ailleurs pas toujours aisé de qualifier exactement une édition" (Johnston und Gilmont, 'Limprimerie et la Réforme à Anvers' (siehe oben, Anm. 113), S. 210-211). An anderer Stelle scheint A.G. Johnston den geringen konfessionellen Charakter der meisten Bibelübersetzungen zu übersehen und scheint (zu Unrecht) eine \%weiteilung anzunehmen: "De l'aveu général, les versions catholiques ont pu être achetées par des prêtres et des églises paroissiales, mais les textes catholiques ne représentent qu'un ticrs de la production totale. La grande majorité des Bibles néerlandaises comportent des traces de protestantisme et la plupart d'entre elles sont interdites dans les différents Indices librorum prohibitorum. Des marchés officiels comme ccux de l'Églisc lcur sont fermés; ils ont donc été achetés par la population elle-même" (Johnston, "L'imprimerie et la Réforme aux Pays-Bas' (siche oben, Anm. 33), S. 170-171).

${ }^{120}$ Nicolas Coppin oder Niclaes Coppijn (alias Meuran) kam aus Mons (Bergen) im Hennegau, dem südlichen, französischsprachigen Teil der Niederlande. Er schloss 1497 sein Studium als magisler artium am Falkenkolleg ('Valkcollege') in Löwen ab. Dort blieb er als Philosophiedozent, während er - wie damals üblich — glcichzeitig Theologie studicrte. 1510 wurde er Regent des Falkenkollegs. 1513 wurde er Doktor der Theologic indem er Rektor der Lniversität e facultate artium war. 1519 oder 1520 übernahm Nicolas Coppin den Platz. Adriaan van Utrechts im Kapitel der SintPieterskerk und die dazugehörende Prebende, narhdem Adriaan zum Kardinal ernannt worden war. 1520 wurde Coppin auch zum Dekan des Kapitels gewählt und anschließBend zum Vize-Kanzler der Universiät. Mit seiner Prebende verband sich ein I ehrstuhl für Thcologic. Noch im gleichen Jahr, 1520, wurde er in das collegium strictum der theologischen Fakultät aufgenommen, erhielt aber eine Befreiung von Vorlesungen, um sich sciner Regentschaft am Falkenkolleg widmen zu können. Am 17. Juni 1524 wurde er (zusammen mit zwei Kollegen) vom Papst zum Gencralinquisitor der Niederlande ernannt. Die Befugnisse Coppins erstreckten sich besonders über Brabant und Holland. Obwohl ursprünglich französischsprachig, müssen wir doch annehmen, dass er Niederländisch beherrschte. In diesem Zusammenhang ist die Befragung des der Ketzerei verdächtigten Jan de Backer aus Woerden interessant. Coppin begann scin Verhör mil der Frage: "Utrum vis, mi Joannes, latine an vernacule loquamur?" (Fredericq, Hg., Corpus Inquisitionis, Band 4 (siehe oben, Anm. 1), S. 412). Die Frage, wie gründlich Coppin Niederländisch beherrschte ist wichtig, da er die Rechtgläubigkeit von Bibelübersetzungen auf Französisch wie Niederländisch beurtcilte. Man könntc den Eindruck bekommen, dass wir über Coppin wenig oder nichts wissen, da er keine theologischen Schriften hinterlassen hat. Er war ja vor allem praktisch auf dem Gebiet der Inquisition aktiv. Was Bibelubersetzungen in der Volkssprache betrifft, so scheint er eher eine liberale Auslegung der Plakate vertreten zu haben. Nicolas Coppin starb am 16. Juni 1535 (Henri De Jongh, L'ancienne Faculté de Théologie de Louvain au premier siècle de son existence (14.32-1540) (Löwen, 1911), S. 160-161; Catherine F. Gunderson und Peter G. Bictenholz, 'Nicolas Coppin', in Contemporaries of Erasmus. A Biographical Register of the Renaissance and Reformation, $\mathrm{Hg}$. Bietenholz und Thomas H. Deutscher, Band 1: A-E (Toronto, 1985), S. 338. 
Nach Ablauf einiger Jahre wurde deutlich, dass die weltlichen und gcistlichen Autoritäten doch etwas Ordnung in das Chaos der Bibelübersetzungen bringen wollten. Statt hinter publizierten Bibelübersetzungen herzulaufen, wollten die Behörden, wie oben angedeutet, dergleichen Veröffentlichungen vorab auf ihre Orthodoxie prüfen. Aber auch dies ließ noch Raum für eine Diskussion. Schr gut veranschaulichen diese Politik die zwei wichtigsten Ausgaben, die in dieser Phase aus der Druckerpresse kamen. Die Liesveltbibel von 1526 war die erste vollständige gedruckte (und illustriertc) niederländische Bibel, dic sich in großen Teilen für das Alte Testament und für das gesamte Ncue Testament auf die Lutherbibel Deutsch stützte und diese ganz neu übersetztc. ${ }^{21}$ Die Liesveltbibel von 1526 war die erste niederländische Bibel, in der dic dcuterokanonischen (sogenannten apokryphen) Bücher herausgenommen wurden, hinter dic kanonischen Bücher. Auch für seine Illustrationen nahm Liesvelt die Ausgabe der Lutherbibel zum Vorbild. Die Löwener Zensoren hatten dieses Exemplar von Liesvelts Ausgabe geprüft, eine Anzahl Korrekturen vorgeschlagen und ihre Erlaubnis für eine Neuauflage gegeben, als ihre Korrekturen aufgenommen waren. Obwohl die Liesveltbibel dem nicht genügte, wurde sie doch durch das Plakat von 1529 nicht ausdrücklich verboten und kam niemals auf den Index. Die Gründe dafür könnten gewesen scin, dass diese Ausgabe auf der Titelscite nur die schlichte Anpreisung 'Dat oude en dat Nieuwe Testament' zeigte, aber sonst keine Vorreden, keine Anmerkungen oder Zusammenfassungen, die reformatorisches Gedankengut hätten enthalten können, enthielt. ${ }^{122}$

Willem Vorsterman hatte sich zur Aufgabe gestellt, die Anmerkungen der Löwener Thcologen zur Liesveltausgabe von 1526 in eine neue Ausgabe einzuarbeiten. ${ }^{123}$ Dic cbenfalls schön bebilderte Vorsterman-

121 De Bruin, De Statenbijbel (siche oben. Anm. 2), S. 94-103; Den Hollander, De Nederlandse bïbeluertalingen (siehe oben, Anm. 2), S. 25-26; 33; 224; 326-329. Den Hollander erwähnt, dass Sieben unterschiedene Quellen für die entgültige Fassung der Liesveltbibel genützt worden sind (Den Hollander, Verboden bijbels (siche oben, Anm. 3), S. 6).

${ }_{122}$ Den Hollander, De Nederlandse bijbelvertalingen (siehe oben, Anm. 2), S. 26; Den Hollander, 'Dat Oude ende dat Nieuwe Testament (1526). Jacob van Liesvelt en de nieuwe markt voor bijbels in de zestiende ceuw', Jaarboek voor Nederlandse boekgeschiedenis 6 (1999), 105-122; Den Hollander, Verboden bijbels (siehe oben, Anm. 3), S. 19.

123 De Hoop Scheffer, Geschiedenis der kerkhervorming in Nederland (siche oben, Anm. 96), S. 273; Cornelis Augustijn, 'De Vorstermanbijbel van 1528', Nederlands Archief voor Kerkgeschiedenis 56 (1975-1976), 78-94; De Bruin, De Statenbizbel (siehe oben, Anm. 2), 
bibcl erschien Ende Oktober 1528. ${ }^{124}$ Bereits auf der Titelseite wurde die Intention der Ausgabe in Form einer Anzeige kurz zusammengefasst: Der Text der Bibel sei auf Grundlage der Vulgata korrigiert und am Rand seien Varianten aufgenommen, die auf den griechischen oder hebräischen Urtext zurückgingen. Auf dem Titelblatt prangte das Wappen und der Kardinalshut von Ximenez de Cisneros, dem Förderer der Polyglotta Complutensis. Zudem konnte Vorsterman auf dem Titelblatt mit einem "cum gratia et privilegio" aufwarten, dass dreizehn Tage nach dem Erscheinungstag, dem 9. November 1528, aufgrund einer positiven Würdigung durch den Löwener Theologen Nicolas Coppin und Antwerpener Schultheiß Claes van Lyere zuerkannt worden war. Die Vorstermanbibel präsentierte sich damit als eine offiziell autorisierte Bibelübersetzung und der Drucker/ Herausgeber Willem Vorsterman erhielt für drei Jahre (bis 1531) das Monopol, diese konkrete Ausgabe zu drucken und zu verkaufen.

Auch in einem Vorwort erläuterten die "correctuers deser translatien" ihre genaue Arbeitsweise: Korrektur des niederländischen Textes auf der Grundlage des lateinischen Textes (Vulgata) und am Rand Anfügung einer Reihe Varianten auf der Grundlage des hebräischen und griechischen Originals, um den autorisierten Text zu vertiefen und zu crklären. Für dic Varianten hatten dic "correctuers" nach eigener Aussage die Polyglotta Complutensis benutzt.

Bei näherem Hinsehen scheint es so zu sein, als hätten die "correctuers" den hebräischen und griechischen Urtext der Polyglotta Complutensis nicht herangezogen. Der Text der Vorstermanbibel beruht auf einer niederländischen Lutherübersetzung (die über das deutsche Original allerdings doch auf den hebräischen und griechischen Urtext zurückgriff). Was das Alte Testament betrifft, gingen Vorstermans Korrektoren, wie angegeben, an erster Stelle von der Liesveltbibel aus. Für die Korrektur des Alten Testaments im Sinne der Vulgata zogen sie auch die 1525 von Hans (1) Ruremund herausgegebene Übersetzung des Alten Testaments heran, die auf die Delfter Bibel

S. 111-118; Den Hollander, De Nederlandse bïhelvertalingen (siche oben, Anm. 2), S. 1-2; 90-92; 226 und 350-357.

${ }^{124}$ Das Altc Testament trägt als Datum den 27. Oktober 1528 und das Neue Testament den 28. Oktober 1528. Dieses Neue Testament war eigentlich bereits die zweite Auflage einer Ausgabe, dic zum crsten Mal im Juli 1528 erschienen war. Diese Juli-Edition war ein Gemeinschafisunternehmen mit Jan Seversz. (Den Hollander, De Nederlandse bijbelvertalingen (siehe oben, Anm. 2), S. 90-91; 226; 356-357). 
von 1477 und damit auf die Vulgata zurückging. ${ }^{125}$ Cornelis Augustijn weist außerdem darauf hin, dass im Text der prophetischen Bücher und in den Varianten am Rand der Finfluss der so genannten 'Wormscr Prophetenbibel' von Denck und Hätzer nachzuweisen sei. ${ }^{126}$ Dieses Buch hatte eine spiritualistische T'endenz, eine spezifische theologische Auffassung, die sonst nicht unbedingt in der Vorstermanbibel begegnet. Die deuterokanonischen (sogenannte apokryphe) Bücher des Alten Testamentes hatten übrigens den selben Rang wie in der Vulgata. Der Text des Neuen Testamentes ist eine fast wörtliche Übernahme der Ausgabe von Christoffel van Ruremund von 1526, dic auch auf den Luthertext zurückging, aber kaum Anmerkungen enthielt. ${ }^{127}$ Obwohl die Absicht gewesen war, den Vulgatatext zu bieten und alternative Übersetzungen auf der Basis des 'hebräischen' oder 'griechischen' Textes am Rand zu drucken, waren aufgrund von Zeitmangel, Missverständnissen und Ungenauigkeiten die vorgeschlagenen Korrekturen anhand des Vulgatatextes nicht überall im Text aufgenommen worden und so kam die Lutherübersetzung im Text noch sehr stark durch. ${ }^{128}$ Vorsterman war sich offenbar dieses Übels bewusst und, um sich vorab gegen mögliche Kritik zu schützen, brachten die "correctuers" im Vorwort und durch die nachträgliche Korrektur verschiedene Erklärungen und Entschuldigungen für Passagen und Eingriffe an, die als weniger 'orthodox' gedeutet werden könnten. Außerdem wurde auf die Setzer hingewiesen,

${ }^{125}$ De Bruin, De Statenbijbel (siche oben, Anm. 2), S. 116 ; Augustijn, 'De Vorstcrmanbijbel van 1528' (siehe oben, Anm. 123), S. 82-84.

126 Augustijn, 'De Vorstermanbijbel van 1528' (siehe oben, Anm. 123), S. 84. Vgl. auch: Cornelis Augustijn, Erasmus der Humanist als Theologe und Kirchenreformer [Studies in Medieval and Reformation Thought 49] (Leiden, 1996), S. 125-127: Augustijn formuliert die Hypothese, dass Vorsterman die nicderländische Übersetzung der Wormser Prophetenbibel womöglich vom nordniederländischen Humanisten Gerard Geldenhouwer erhalten habe, der sich 1527 in spiritualistischen Kreisen in Worms aufhielt und seiner Korrespondenz nach die deutschen Prophetenbücher von Denck und Hätzer ins Niederländische übersetz.t hat. Nach seinem $\Lambda$ ufenthalt in Worms soll er nach Antwerpen gegangen sein, wo er vielleicht seine niederländische Prophetenübersetzung Vorsterman zur Verfügung stellte.

${ }_{127}$ Sowohl C.C. de Bruin als auch S.W. Bijl deuten an, dass die Vorstermanbibel deutliche Anklänge an Lettersnijders Erasmusedition von 1524 aufweist (De Bruin, De Statenbijbel (siehe oben, Anm. 2), S. 111; Bijl, Erasmus in het Nederlands (siehe oben, Anm. 2), S. 46-47).

${ }_{128}$ Deswegen redet C. Augustijn von einer "Übersetzung in reformatorischem Stil". Ein Beispiel dafür ist dic angeführte Übersetzung von Matthäus 4,17 als "Hebt berou" (Augustijn, 'De Vorstermanbijbel van 1528' (siche oben, Anm. 123), S. 86; unsere Übersetzung). 
die in Abwesenheit der "correctuers" nicht alle Verbesserungen im Bibeltext aufgenommen hätten. So scheint es, dass vor allem die Arbeiter in der Druckerei die Schuld zugeschoben bekommen haben. Doch geht es um mehr: Im Prolog haben die Bearbeiter große Teile von Luthers Vorwort zum Pentateuch (1523) übernommen, aber den konfessionell sensiblen Gegensatz zwischen Gottes Gnade und den guten Werken als alternative Antworten auf menschliche Sündhaftigkeit ausgelassen und eine Ermahnung eingefügt, dic kirchlichen Gebote, die dem Evangelium nicht widersprachen, zu achten und weltlicher und kirchlicher Obrigkeit mit Ehrerbictung zu begegnen.

$\mathrm{Ob}$ die Bearbeiter der Vorstermanbibel tatsächlich den "durch Luther beeinflussten biblisch-humanistischen Kreisen"129 angehörten, wissen wir nicht. Wie dem auch sei, der Löwener Theologe Nicolas Coppin und der Antwerpener Schultheiß Claes van Lyere gebrauchten 1528 bewusst dic Lückc, die die kaiserlichen Plakate für niederländische Bibelübersetzungen zuließen und gaben Willem Vorsterman sein "consent". Im Nachhincin kann dies als ein leichtfertiger (und für Protestanten lächerlicher) Entschluss crschcinen, aber er passte genau in den Kontext der Diskussion darüber, was cine katholische Bibelübersetzung aufnehmen durfte und was nicht. Dic Behörden der Stadt Antwerpen wollten die Stellung ihrer Hafenstadt als offenes Handelszentrum sicher stellen. Auch die Löwener Theologen waren in dieser Phase noch zu Kompromissen darüber bereit, was eine annehmbare Bibelübersetzung sein konnte. Argwohn schien nur aufzukommen, wenn ausgesprochen reformatorische Glossen und Vorreden vorkamen. Willem Vorsterman betreute ein Jahr später, 1529, eine Ausgabe nur des Neuen Testamentes, die anhand der Ausgabe von Michicl Hillen van Hoochstratens korrigiert, also ordentlich im Sinne der Vulgata angeglichen und somit seines "cum gratia et privilegio" würdig war.

Die vorherige Approbation cincr Ausgabc, wie dies ab 1528 mit der Vorstermanbibel geschah, wurdc durch das Plakat von 1529 allen Bibelübersetzungen in die Volkssprache, dic in den Niederlanden erscheinen sollten, auferlegt. Der gerade genannte Michicl Hillen van Hoochstraten, dessen zweite niederländische Übersetzung des Neuen Testamentes (1530) sich noch stärker an dic Vulgata anpasste, hatte

${ }^{129}$ Augustijn, 'De Vorstermanbijbel van 1528' (siche oben, Anm. 123), S. 94 (unsere Übersetzung). 
keine Schwierigkeit cin "cum gratia et privilegio" zu erhalten. Diese Zulassung gab es auch für die zwei Editionen Michiel Hillens von 1531. 130 Auch Willem Vorsterman wollte die offizielle Approbation seiner Ausgaben sicher stcllen. Bereits 1529 berief er sich auf die Ausgabe Michicl Hillens, um seine Edition von 1528 mehr an die Vulgata anzupassen. Ab 1530 übernahm Vorsterman für seine Ausgaben sogar komplett den Text Michiel Hillens von 1527. Diesc Vorstermanbibel sollte mehrere Neuauflagen erleben und noch jahrelang bei reformatorisch Gesinnten wie bei Katholiken und den vielen Unentschlossenen populär bleiben. ${ }^{131}$ Selbst Cornelis Henricsz. Lettersnijder hat sich ganz den Forderungen der Obrigkeit angepasst und gab 1533 zusammen mit Henrick Peetersen van Middelburch eine zweitc Ausgabe seines Neuen Testamentes heraus, die gewissenhaft der von Michiel Hillen vom Oktober 1531 folgte. Die Ironie dieser Geschichte ist, dass es genau Lettersnijders erste Ausgabe von 1524 war, die Hillen 'vulgatisiert' hatte. ${ }^{132}$ Dass die konfessionelle Polarisierung auch beim Bibelgebrauch immer stärker zum Ausdruck kam, zeigen gerade dic Ausgaben Jacob van Liesvelts, die sich immer mchr an den Lutherausgaben ausrichteten. Für die Auflage von 1532 hat die Antwerpener Stadtbehörde Liesvelt noch ein "cum gratia et privilegio" geben können. Der Drucker aber setzte diese Zulassung auch auf die weiteren Bibelausgaben, einschließlich der von 1542, die ausdrückliche reformatorische Randbemerkungen enthielt. Liesvelt wurde letztlich enthauptet (1545), weil er ohne vorhergchende Erlaubnis der Zensoren Bücher herausgegeben hat. ${ }^{133}$

${ }^{130}$ De Bruin, De Statenbijbel (siehe oben, Anm. 2), S. 108-109; Den Hollander, De Nederlandse bijbelvertalingen (siehe oben, Anm. 2), S. 81; 227-228; 364-366; 375-379.

131 De Bruin, De Statenbïbel (siehe oben, Anm. 2), S. 118-120; Den Hollander, De Nederlandse bijbelvertalingen (siehe oben, Anm. 2), S. 93-94; 226-228; 358-360; 369374; 382-386; 397-401; 423-427; 487-496.

132 Den Hollander, De Nederlandse bijbelvertalingen (siehe oben, Anm. 2), S. 58; 230; 408-410; Den Hollander, 'Het Nieuwe Testament. Cornelis Henricsz. Lettersnijder' (siche oben, Anm. 104), S. 178-185; Den Hollander, 'Recently Discovered: A Copy of the 1533 Edition of the New Testament by the Delft Printer, Cornelis Henricsz Lettersnijder', Quaerendo. A Quarterly Goumal from the Low Countries Devoted to Manuscripts and Printed Books 25 (1995), 310-312.

${ }^{133}$ Siehe: Wim François, 'Jacob van I iesvelt, Martyr for the Evangelical Belief?', in More than a Memory. The Discourse of Martyrdom and the Construction of Christian Identity in the History, Hg. Johan Leemans [Annua Nuntia Lovaniensia] (Löwen, erscheint 2005). Auch: De Bruin, De Statenbïbel (siche oben, Anm. 2), S. 98; 102; Den Hollander, De Nederlandse bïbeluertalingen (siche oben, Anm. 2), S. 34-36; 229-231; 393-396; 416 422 ; 428-434; 448-449; 458-459; 480-486; 500-503. 


\section{Schluss}

Seit dem Aufkommen des Luthertums wollten die weltlichen und geistlichen Autoritäten in den Niederlanden die Veröffentlichung und Zirkulation von Büchern, in denen die neue Lehre verkündet wurde, aufhalten. Auch dic Bibelproduktion musste sorgfältig überprüft werden, denn die Obrigkeit begriff, dass Luthers Lehre eine eigene I csart der Heiligen Schrift vertrat. Dass einfache Laien, zum Beispiel in den 'Konventikeln', dic Bibel im Sinne der neuen Ideen (hören) lesen und auslegen könnten, wurde als eine mögliche Quelle für Ketzcreien und Irrlehren betrachtet. Dic Ketzerplakate in den Niederlanden stellen dennoch kein allgemeines Verbot aller Bibelübersetzungen in der Volkssprache, noch sogar cinc für Ausgaben die auf der Lutherbibel basierten, dar. Nlerdings gab cs ab 1526 ein strenges Verbot für niederländische und französische Übersetzungen der Luthcrbibel, die auch reformatorische Glossen, Summarien und/oder Vorreden enthielten. Ein wichtiger Fixpunkt, der dic Bibelpolitik der ersten Jahre zusammenfasst, ist das Ketzerplakat von 1529. Dies enthielt eine Art 'Proto-Index', der wahrscheinlich auf Löwcncr Theologen zurückging und die Ausgaben dreier Drucker/Herausgeber mit der Zensur behaftete: Adriaen van Berghen, Christoffel van Ruremund und "Johannes Zel". In den Niederlanden ist kein Drucker dieses Namens bekannt, aber womöglich waren Hans (1) van Rurcmund (1525), Jan (1) van Ghelen (1526) oder sogar Hicro Fuchs (1525) gemeint. Die Ausgaben dieser Drucker/Herausgeber wurden verboten, da dic Löwener Theologen zweifelsohne bemerkt hatten, dass deren Vorreden, Summarien und/oder Glossen lutherische Irrlchren enthielten. Doch waren diese Drucker/Herausgeber vorsichtig gewesen: Sie hatten diese 'paratextuellen' Elemente nicht auf der Titelseite angekündigt. Auf den Besitz dieser verbotenen Bibelübersetzungen wic auch aul den Besitz anderer reformatorischer Literatur stand seit 1529 eindeutig die Todesstrafe, was eine bedcutende Verhärtung im Vergleich mit dem Standpunkt früherer Plakate darstellte. Außerdem wurde durch das Plakat von 1.529 auch offiziell verkündet, dass für jede Ubersetzung in die Volkssprache dic vorherige Zulassung durch dic Obrigkeit Bedingung war, eine Praxis, dic übrigens einige Monate zuvor de facto eingeführt worden war und einc gewisse Sicherheit für Herausgeber und Leser von Bibeln garantieren sollte.

Vicle örtliche Verwaltungen gingen schnell auf Iücken cin, die dic kaiscrlichen Plakate boten. Das geschah im Fall der Stadt 
Antwerpen, wo die meisten Bibeldrucke entstanden. Die Stadt wollte den Druckereien nicht ohne weiteres Zügel anlegen und zudem das Image der offenen Hafenstadt so lange wie möglich bewahren. Die Zentralregierung sah ihrerseits zweifelsohne cin, dass die Gesundheit des Antwerpener Kapitalmarktes Icbenswichtig war für die finanziellen Einkünfte des Staates. Antwerpener Drucker konnten ihre Bibelübersetzungen weiterhin auf den Markt bringen, und diese Ausgaben fanden großen Absatz. bei Katholiken, Leuten humanistischer Gesinnung, I cuten die mit Luther sympathisierten und andere religiöse Dissidenten. Vicle Drucker, wie M. Hillen van Hoochstraten und W. Vorsterman, würden sich am Ende für cinen niederländischen Text entscheiden, der sich eng der Vulgata anschloss. Aber auch Bibelausgaben, die eher dem Luthertext folgten, wie dic von Licsvelt, bekamen problemlos ihr "cum gratia et privilcgio", solange der 'l'ext nicht durch Glossen, Vorreden und Summarien cine 'ketzerische' Interpretation erhielt. Die zuständigen Löwener Theologen arbeiteten einer liberalen Auslegung der Plakatc also nicht entgegen, cher im Gegenteil. Bibelübersetzungen in der Volkssprache waren sicherlich nicht ihr wichtigster point of concem. In der Praxis - mehr als in der Theoric anerkannten die magistri das Recht der Katholiken, die Bibel in der Volkssprache zu lesen. Der Löwener Theologe und Inquisitor Nicolas Coppin ist dic Personifizierung dieser tolcranten Vorgehensweise. Mit Johnston und Gilmont können wir feststellen: "La sérénité avec laquelle les imprimeurs anversois les [= bibles flamandes et françaises] multiplient avant 1545 cxclut l'éventualité d'une répression féroce. L'attitude des autorités catholiques face aux versions de la Bible en languc populaire n'est pas aussi tranchée qu'on le dit parfois". ${ }^{131}$ Dennoch müssen wir festhalten, dass gerade im sechzehten Jahrhundert in Dissidentenkreisen das Vorurteil bestand, Gläubigen würde von der Staatsmacht verboten, die Bibel in der Iandessprache zu lesen. Auch heute noch halten sich in bestimmten wissenschaftlichen Kreisen hartnäckige Vorurteile über konscrvative Löwener Theologen ${ }^{135}$ und

131 Johnston und Gilmont, 'L'imprimeric et la Réforme à Anvers' (siehe oben, Anm. 113), S. 210.

1:35 A. Duke ordnet dic Löwener Theologen vielleicht etwas unnuanciert der Scitc rigoroser Ketzerpolitik zu, wenn er schreibt: "... but in religion he [= Charles V] aligned himself with the conservative theologians of Louvain and the mendicant opponents of Luther" (Duke, Reformation and Revolt (siehe oben, Anm. 6), S. 138). 
über ein striktes Verbot für Katholiken, die Bibel in der Volkssprache zu lesen. ${ }^{136}$

Die weitere Entwicklung der Bibelpolitik der Löwener Theologen in den dreißiger und vierziger Jahren war nicht das Anliegen dieses Artikels. Nach der Studie Den Hollanders über den Index von Löwen von 1546 scheint es so, dass die Löwener Theologen, konfrontiert mit einer wachsenden Zahl von Bibelübersetzungen in der Volkssprache, im Prinzip immer noch Ausgaben in den Blick nahmen, die Vorreden, Summarien und Glossen mit reformatorischem Einschlag enthielten, aber dass die Theologen ihr Urteil offenbar oft auf eine eher oberflächliche Untersuchung der Titelseite stützten und besonders abweisend reagierten, wenn (verbotene) paratextuelle Elemente auf der Titelseite angekündigt wurden. ${ }^{137}$

136 Wir haben bercits darauf hingewiesen, dass selbst Anmerkungen in der neueren Literatur nuancicrt werden müssen: Goosens, Les inquisitions, Band l (siche oben, Anm. 1), S. 5; Fühner, Die Niederlande (siehe oben, Anm. 1), S. 183. Auch C.C. de Bruin sprach noch zu undifferenziert wenn er meint, dass zwar kein Verbot von Bibelausgaben in der Volkssprache bestand, aber dass de facto alle Ausgaben verdächtig waren (Dt Bruin, De Statenbijbel (siehe oben, Anm. 2), S. 131).

${ }^{137}$ Für eine Weiterführung: Den Hollander, Verboden bübels (siehe oben, Anm. 3). 